\title{
Flaming the fight against cancer cells: the role of microRNA-93
}

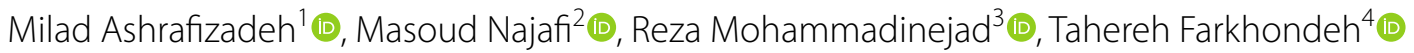 \\ and Saeed Samarghandian ${ }^{5^{*}}$ (])
}

\begin{abstract}
There have been attempts to develop novel anti-tumor drugs in cancer therapy. Although satisfying results have been observed at a consequence of application of chemotherapeutic agents, the cancer cells are capable of making resistance into these agents. This has forced scientists into genetic manipulation as genetic alterations are responsible for generation of a high number of cancer cells. MicroRNAs (miRs) are endogenous, short non-coding RNAs that affect target genes at the post-transcriptional level. Increasing evidence reveals the potential role of miRs in regulation of biological processes including angiogenesis, metabolism, cell proliferation, cell division, and cell differentiation. Abnormal expression of miRs is associated with development of a number of pathologic events, particularly cancer. MiR-93 plays a significant role in both physiological and pathological mechanisms. At the present review, we show how this miR dually affects the proliferation and invasion of cancer cells. Besides, we elucidate the oncogenesis or oncosuppressor function of miR-93.
\end{abstract}

Keywords: Cancer therapy, MicroRNA, Oncogenesis, Oncosuppressor, Signaling pathway

\section{Introduction}

Cancer is defined as a process that cells undergo uncontrolled proliferation due to abnormal alterations in genetic material. It seems that both internal and external factors are involved in generation of cancer [1]. It has been demonstrated that the enhanced proliferation of cancer cells continues in spite of inhibition of external or internal factors [2]. Accumulating data demonstrates that genetic alterations are mainly responsible for the generation of cancer [3]. During cell proliferation, there are certain points that regulate cell division. Induction of cancer results in lack of response to these modulators $[4,5]$. This nonstop proliferation produces benign and malignant tumor cells that would compete for nutritional sources with normal cells [6]. The metastasis nature of

\footnotetext{
*Correspondence: samarghandians1@nums.ac.ir

${ }^{5}$ Healthy Ageing Research Center, Neyshabur University of Medical Sciences, Neyshabur, Iran

Full list of author information is available at the end of the article
}

cancer cells defines them as malignant or benign. Cancer cells are capable of moving to the various organs and tissues of body via lymphatic chain. This mechanism is known as metastasis. The malignant tumor cells are able to significantly invade other tissues and organs while benign tumor cells are restricted to a certain location [7, 8]. In respect to the potential role of genetic alterations in induction of cancer, investigation of genetic material reveals that microRNAs (miRs) play a remarkable role in cancer progression and migration [9-12].

MiRs are short non-coding RNA molecules with the length of 19-24 nucleotide bases capable of gene regulation at the post-transcriptional level $[13,14]$. After the discovery of miRs in 1993 in Caenorhabditis elegans, much attention was made towards them to identify and determine their location in genome [15-17]. It appears that this focus on miRs emanates from their critical role in regulation of important biological processes including programmed cell death (both apoptosis and autophagy) $[18,19]$, cell growth and division $[20,21]$, cell 
differentiation [22, 23] and metabolism [24]. A growing body of evidence demonstrates that miRs recognize their target genes by binding to the $3^{\prime}$-untranslated region [2527]. Based on the role of miRs in biological processes, abnormal expression of miRs is associated with development of a number of pathologic events such as cancer $[28,29]$, cardiovascular diseases [30, 31] and neurological disorders (NDs) [32, 33]. The alteration in expression leads to the application of miRs as biomarkers for identification of various pathological conditions, particularly cancer. For instance, miR-141 is one of the potential miRs involved in suppressing the malignancy and invasion of laryngeal cancer cells that undergo down-regulation in this cancer [34]. MiR-132 is capable of significant reduction in the viability and proliferation of renal carcinoma cells [35]. These studies highlight this fact that identification of miRs and their subsequent targeting is a promising strategy in treatment of cancer as a life-threatening condition [36].

\section{Biogenesis of microRNAs}

It seems that a number of stages should be performed to produce a mature miR from a long primary transcript. First of all, RNA polymerase II/III synthesizes a hairpin structure known as primary-miR (pri-miR) [37]. Next, RNase III family enzymes (Dicer and Drosha) use pri$\mathrm{miR}$ as a substrate to produce precursor-miR (pre-miR) with a length of about 70 nucleotide bases [38]. After the translocation of pre-miR into cytoplasm via Exportin-5 (Exp5), Dicer enzymes lead to the formation of a short mature miR [39]. This mature miR is not active and should follow a variety of other stages to be activated. The entering of mature miR into miR-induced silencing complex (miRISC) by transactivation-responsive RNA-binding protein (TRBP) results in the interaction between DICER and Argonaute (Ago) proteins. Now, the mature miR is active and miRISC complex chooses a single strand of mature miR to bind to the target gene leading to the translation inhibition or degradation $[40,41]$.

\section{MicroRNA and cancer development}

Cancer progression is caused by several changes in oncogenes and tumor-suppressor genes during several years [42]. Numerous studies have indicated a main role for miRNAs in the cancer pathogenesis [42]. miRNAs can affect cancer progression through regulation of cell growth and apoptosis [42]. The miRs are used as biomarkers for assessing cancer prognosis and drug efficacy [42]. Many miRs act as oncogenes or tumor suppressors in the cancers process [42]. Thus, the increasing knowledge on these miRs helps us in cancer therapy [42].

\section{Expression alteration of microRNAs in cancer}

Overall, miRs are divided into two major categories known as oncosuppressor and oncogenesis miRs. As it is obvious, oncosuppressor miRs are involved in suppressing the migration and invasion of cancer cells, whereas oncogenesis miRs contribute to the progression and proliferation of cancer cells [42]. There is the third type of miRs known as apoptomiR that can regulate the apoptotic cascade in cancer cells [43]. In tumor cells, the expression of these miRs undergoes alterations. It has been demonstrated that tumor cells are able to enhance the expression of oncogenesis miRs and reduce the expression prolife of oncosuppressor miRs to ensure their malignancy and invasion [44-47]. MiR-152 is an oncosuppressor miR that enhances the potential of chemotherapy by sensitizing cancer cells to apoptotic cell death [48]. MiR-205-5p is another oncosuppressor miR involved in inhibition of proliferation of breast cancer cells [49]. It is held that the down-regulation of oncosuppressor miRs occurs during cancer growth and metastasis $[50,51]$.

\section{MicroRNA-93: a brief introduction}

Accumulating data demonstrates that miR-93 plays a significant role in both physiological and pathological conditions. Several studies have been conducted to show the down-regulation/upregulation of miR-93 in diseases and health. A recent study shed some light on the role of miR-93 in NDs. It is held that miR-93 contributes to the inflammation by affecting the proliferation of microglia and blood levels of miR-93 are considered as reliable indexes for diagnosis and prediction of functional recovery of acute ischemic stroke $[52,53]$. The upregulation of miR-93 occurs in cerebral cortex and hippocampus after transient brain injury [54, 55]. These alterations show the potential of miR-93 of being used as a prognosis signature of transient brain injury [56]. Besides, the expression of miR-93 elevates in the postischemic brain [57]. In respect to the involvement of miR-93 in ischemic injury, application of miR-93 inhibitor is associated with attenuation of the injury by enhancing the antioxidant defense system through nuclear factor erythroid 2-related factor 2 (Nrf2) signaling pathway [58]. A growing body of evidence exhibits that miR-93 predisposes to immune system disorders by stimulation of secretion of cytokines, chemokines and growth factors [59, 60]. Furthermore, miR-93 is able to reduce the expression of signal transducer and activator of transcription 3 (STAT3) to suppress neuroinflammation and consequently, NDs [61]. MiR-93 involves in amelioration of cardiovascular diseases. It appears that miR-93 considerably promotes perfusion recovery and angiogenesis resulting 
in improvement of peripheral arterial diseases [62, 63]. MiR-93 also is capable of targeting macrophages (macrophage M2 polarization) in elevating angiogenesis and arteriogenesis in PAD [64]. Pharmacological and genetic manipulations of miR-93 are of importance in treatment of pathological conditions $[65,66]$. Taking everything into account, it seems that miR-93 has an efficient role in preserving health condition and its abnormal expression is associated with pathologic events. In the next sections, we discuss the impact of miR-93 expression in cancer cells.

\section{MiR-93 in cancer malignancy Lung cancer}

Lung cancer is one of the most challenging problems worldwide with high morbidity and mortality [67]. In spite of huge advancement in diagnosis and treatment of lung cancer, the patients with this life-threatening disorder still have a low 5-year survival rate $[68,69]$. In respect to the involvement of genetic factors in generation of lung cancer, targeting miRs is of importance in its treatment. Circular RNAs (circRNAs) are a kind of transcripts which produce a covalently closed continuous loop [70, 71]. It is held that circRNAs are able to sponge miRs that is due to their miRNA target sites such as Ago2 protein [72-75]. Based on the vital role of circRNAs in regulation of biological processes, they are of interest in treatment of pathological conditions, particularly cancer [52, 76-79]. In the case of lung cancer, circCRI-M1 remarkably diminishes the invasion and malignancy of tumor cells. Due to the Ago2 protein, this circRNA is capable of sponging the miR-93 that in turn, enhances the expression of leukemia inhibitory factor receptor, as a tumor suppressor leading to the reduced metastasis and viability of lung cancer cells [80]. As one of the potential targets of circRNAs, miR-93-5p is affected by circRNF13 in lung cancer cells. CircRNF13 is capable of reducing the proliferation and viability of lung cancer cells by downregulation of miR-93-5p through interacting with Ago2 [81]. Non-small cell lung cancer (NSCLC) is responsible for more than third-to-fourth of lung cancers [82]. Although much improvement has been made in the diagnosis and treatment of this life-threatening disorder, it is still one of the leading causes of death. MiR-93-5p acts as a biomarker in NSCLC. The expression of this miR suggested to be higher in NSCLC patients compared to the healthy ones. Besides, its high expression is associated with poor prognosis and low survival of patients with NSCLC. This is due to the stimulatory impact of miR-93-5p on the migration, proliferation, and invasion of NSCLC cells [83]. Based on the role of PI3K/Akt pathway in cancer progression, this molecular pathway is considered as a downstream mediator of miR-93. In order to elevate the malignancy and invasion of NSCLC cells, miR-93 downregulates the expression of tumor suppressor genes including LKB1, PTEN and CDKN1A to stimulate PI3K/Akt signaling pathway and subsequently, ensure the migration and proliferation of these tumor cells [84]. Neural precursor cell expressed developmentally downregulated gene 4-like (NEDD4L) is considered as a NEDD4-like E3 ubiquitin ligase [85]. The main function of NEDD4L is the regulation of ion channel receptors and transporters [86, 87]. However, accumulating data demonstrates that NEDD4L is capable of modulation of a number of signaling pathways such as tumor growth factor- $\beta$ (TGF- $\beta$ ) [88-91]. It is held that NEDD4L undergoes down-regulation in lung cancer [88]. MiR-93 prevents the expression of NEDD4L to stimulate EMT via TGF- $\beta$ upregulation [92]. Wnt signaling pathway is suggested to be involved in the modulation of cell proliferation and cell differentiation [93, 94]. These important roles have made Wnt signaling pathway as a vital target in cancer therapy [95, 96]. Zinc and ring finger 3 (ZNRF3) is an inhibitor of Wnt signaling pathway [97]. In lung carcinoma, ZNRF3 reduces the expression of Wnt pathway to inhibit the proliferation of tumor cells. Given the role of miR-93 as an oncogenesis miR, this miR inhibits ZNRF3 to ensure the viability of tumor cells [98]. MiR-93 is a biomarker of NSCLC as its expression elevates in the tissues of patients with NSCLC [99].

The disabled homolog 2 (DAB2) is a tumor suppressor gene encoding a mitogen-responsive phosphoprotein. The expression of DAB2 undergoes down-regulation in various cancers and lung cancer is among them [62, 100-104]. Based on the role of miR-93 in enhancing the malignancy of lung cancer cells, this miR downregulates the expression of DAB2 to promote the proliferation and malignancy of these tumor cells [105].

\section{Esophageal cancer}

Esophageal cancer [106] is one of the most malignant cancers and claim the seventh place among other malignant tumors [107]. Both environmental and genetic factors contribute to the progression of EC $[108,109]$. It has been demonstrated that miRs can promote the proliferation and viability of EC cells [110]. Hence, manipulation of miRs can reduce the malignancy of EC cells. A synthetic circRNA resistant to the digestion with RNase R, suppressed the expression of miR-93 as an oncogenesis $\mathrm{miR}$ in EC and resulted in diminished proliferation and migration, and enhanced apoptosis of tumor cells [111]. PTEN plays a significant role in modulation of cell cycle and proliferation. It seems that PTEN exerts an antitumor impact since its expression undergoes down-regulation during cancer progression $[112,113]$. Investigation of molecular pathways demonstrates that miR-93-5p 
enhances the malignancy and proliferation of EC cells by down-regulation of PTEN/PI3K/Akt axis and its downstream targets p21 and cyclin D1 [114]. MiR-93 can be considered as a potential biomarker of EC as its expression enhances in EC cells [115].

\section{Osteosarcoma}

Osteosarcoma (OS) is a malignant tumor among adolescents [116]. The capability of OS cells in metastasis to neighboring cells and tissues leads to the high death and minimal 5-year survival rate among the patients [117, 118]. Long non-coding RNAs (lncRNAs) are another member of non-coding RNAs with the ability of regulating miRs $[119,120]$. It seems that the enhanced expression of lncRNA AWPPH is associated with upregulation of miR-93-3p and subsequently, an increase occurs in the viability and proliferation of OS cells [121]. By induction of miR-93-3p/FZD7 axis, IncRNA AWPPH upregulates the expression of $\mathrm{Wnt} / \beta$-catenin signaling pathway to enhance the migration and invasion of tumor cells [121].

\section{Cervical cancer}

Cervical cancer is at the second place after breast cancer among gynecological malignancies and negatively affects the women's health [122]. Fortunately, we have witnessed a remarkable decrease in the incidence rate of cervical cancer due to the powerful tools in diagnosis and further therapy of this disorder [123, 124]. B cell translocation gene 3 (BTG3) inhibition is a promising strategy by tumor cells to decrease the efficacy of radiotherapy [125]. Moreover, BTG3 is considered as a tumor suppressor and its inhibition enhances the malignancy of cervical cancer cells [126]. There is a reverse relationship between miR-93 and BTG3 expression in cervical cancer cells. By down-regulation of miR-93-5p, an increase occurs in the expression profile of BTG3 to stimulate apoptosis and reduce proliferation and metastasis [127].

\section{Brain tumors}

It is held that miR-93 can be used as a prognostic signature of primary central nervous system lymphoma (PCNSL). This is due to the impact of this miR on the various genes. It appears that miR-93 is able to affect a number of factors such as programmed cell death 1 ligand 2 (PDCD1LG2) associated with cancer immunotherapy, G-protein coupled receptor 137C (GPR137C) and mitogen-activated protein kinase 2 (MAPK2). Investigation of miR-93 expression prolife reveals that patients with low expression of miR-93 have poor prognosis that is maybe due to its impact on PDCD1LG2. This study demonstrates that miR-93 can be considered as a reliable biomarker for prediction of prognosis of patients with PCNSL [128]. Gliomas are one of the most common malignant tumors of brain with high aggressiveness $[129,130]$. The World Health Organization (WHO) has divided gliomas into four grades (I, II, III and IV) and it has been shown that grade IV is more common compared to the other grades [131]. Genetic alterations are partially responsible for the generation and progression of gliomas. LncRNA MEG3 involves in induction of apoptotic cell death in glioma cells and reducing their proliferation and viability by down-regulation of miR-93 [132]. As a downstream target of PTEN, PI3K/Akt signaling pathway is affected by miR-93 to ensure the malignancy of glioma cells. It is held that the expression of miR-93 undergoes upregulation in the tissues of patients with gliomas and is associated with clinicopathologic grade and overall survival of patients. The activated miR93 inhibits PTEN, PH domain leucine rich repeat protein phosphatases (PHLPP) and forkhead box O3 (FOXO3) by targeting $3^{\prime}$-UTR. The inactivation of these pathways leads to the induction of PI3K/Akt that significantly enhances the malignancy of glioma cells [133].

\section{Prostate cancer}

Bioinformatics analysis shows that miR-93-5p functions as an oncogensis miR during prostate cancer progression. Accumulating data demonstrates that suppressing the expression of miR-93-5p is associated with a decrease in proliferation, migration and invasion of prostate cancer cells, while an increase occurs in apoptosis [134]. Disabled homolog 2 (DAB2) participates in modulation of cancer progression by targeting a number of molecular pathways such as Akt and ERK1/2. It has been reported that stimulation of Akt and ERK1/2 remarkably elevates the malignancy and proliferation of prostate cancer cells and exerts anti-apoptotic impact [135-137]. Based on the role of miR-93 in enhancing the malignancy of tumor cells, this miR reduces the expression of DAB2 to upregulate Akt and ERK1/2 signaling pathways [138]. On the other hand, great tea (Camellia sinensis) has high antitumor activity [139]. It seems that inhibition of miR-93 and simultaneous administration of great tea is a potential strategy in treatment of prostate cancer, since great tea upregulates the expression of DAB2 to inhibit Akt and ERK1/2 signaling pathways [138]. It is held that the expression of miR-93 is higher in tumor cells compared to the normal cells making it an appropriate prognostic signature [140]. There a number of genes that are affected by miR-93 and TGFBR2, ITGB 8 and LATS 2 are among them. Accumulating data demonstrates that these three genes are responsible for proliferation and invasion of cancer cells [141-143]. As an oncogenesis miR, miR-93 elevates the proliferation, invasion and metastasis of prostate cancer cells by enhancing the expression of TGFBR2, ITGB8 and LATS2 [144]. Capicua (CIC) is 
a HMG box-containing transcriptional repressor that plays a significant role in preservation of homeostasis [145-147]. Interestingly, studies have revealed the potential role of CIC in pathogenesis of different cancers [148-150]. However, CIC reduces the proliferation and malignancy of prostate cancer cells. As an oncogenesis $\mathrm{miR}$, miR-93 activates $\mathrm{miR}-106 \mathrm{~b} / \mathrm{miR}-375$ to downregulate CIC-CRABP1 leading to the enhanced proliferation and migration of prostate cancer cells [151].

\section{Hepatocellular carcinoma}

A growing body of evidence demonstrates that hepatocellular carcinoma cell (HCC) is a public health difficulty in both developing and developed countries [152, 153]. It is held that the deregulation of lncRNAs is responsible for generation of cancers, particularly HCC and contributes to their malignancy [154-158]. Besides, the resistance of HCC cells to chemotherapy reduces the efficiency of anti-tumor drugs. Expression investigation of lncRNA SNHG16 in both HCC cell lines and tissue revealed the minimal expression of SNHG16. Enhancing the expression of lncRNA SNHG16 demonstrated the reduced expression of miR-93 that in turn diminishes tumor growth in vivo and suppresses 5 -fluorouracil (5-FU) resistant [159]. Multiple studies have shed some light on the impact of IncRNA LINC00472 in cancer malignancy. It seems that upregulation of this lncRNA diminishes the viability and proliferation of breast cancer cells and its low expression is associated with poor prognosis of patients with breast cancer [160-162]. Moreover, reduced expression of IncRNA LINC00472 enhances the migration and invasion of colorectal cancer cells [163]. It appears that miR-93-5p is a target of LINC00472. In order to suppress the malignancy of HCC cells, this lncRNA down-regulates the expression of miR-93-5p/ PDCD4 axis to stimulate apoptotic cell death [164]. TP53INP1, CDKN1A and TIMP2 are able to regulate the proliferation and growth of tumor cells $[165,166]$. It seems that exosomal miR-93 exerts stimulatory impact on the malignancy and invasion of HCC cells by downregulation of TIMP2/TP53INP1/CDKN1A axis [167]. Peroxisome proliferator-activated receptor gamma coactivator-1 alpha (PPARGC1A) is suggested to be involved in generation of a number of disorders, particularly cancer $[168,169]$. This factor contributes to the mitochondrial biogenesis and its expression undergoes inhibition in cancer cells $[170,171]$. In respect to the anti-tumor activity of PPARGC1A, miR-93-5p suppresses its expression to enhance the proliferation and malignancy of HCC cells [172]. Programmed cell death 4 (PDCD4) induces programmed cell death to reduce the viability of cancer cells [173]. The expression of PDCD4 undergoes downregulation in a number of cancers [174]. This protein remarkably diminishes the invasion of tumor cells by EMT modulation [175]. Notably, miR-93 inhibits PDCD4 by directly targeting its $3^{\prime}$-UTR resulting in enhanced migration of tumor cells via EMT stimulation $[176,177]$.

\section{Breast cancer}

Breast cancer is one of the leading causes of women's death with high metastasis capability $[178,179]$. There are a number of molecular signaling pathways involved in regulation of biological processes such as cell proliferation and cell differentiation, and signal transducer and activator of transcription (STAT) is one of them $[180,181]$. It has been revealed that STAT signaling pathway undergoes deregulation in a variety of disorders, particularly cancer $[182,183]$. It seems that STAT3 is a target of miR-93 in breast cancer cells. LncRNA H19 inhibits the down-regulation of miR-93 to enhance the expression of STAT3 signaling pathway leading to the increased proliferation and metastasis of breast cancer cells [184]. Besides, the upregulation of exosomal miR-93 in ductal carcinoma in situ (DCIS) patients is a prognostic signature of breast tumors [185]. One of the troublesome problems faced in cancer therapy is the resistance of cancer cells to chemotherapeutic agents [186, 187]. Expression evaluation of miR-93 in breast cancer cell lines showed that miR-93 undergoes down-regulation in these tumor cells. Enhancing the expression of miR-93 is associated with high anti-tumor activity of chemotherapeutic agents by reducing the expression of $\mathrm{Bcl}-2$ and P-glycoprotein (P-gp) [188]. Accumulating data demonstrates that miRs contribute to the stimulation of EMT in breast cancer [189-192]. Moreover, EMT mechanism induces drug resistance in cancer cells [193-196]. On the other hand, PTEN enhances the chance of drug resistance by EMT induction [197, 198]. MiR-93 mediates the resistance of breast cancer cells into doxorubicin (DOX) by EMT induction via targeting PTEN [199]. Another study puts emphasis on the downstream target of PTEN, so that during breast cancer progression, PTEN upregulation inhibits PI3K/Akt signaling pathway. However, miR-93 reduces the expression of PTEN to upregulate the expression of PI3K/Akt signaling pathway leading to the promotion of cell proliferation [200]. Previously, we mentioned that miR-93 induces drug resistance by activation of EMT mechanism. However, a study conducted by Xiang and colleagues provides controversial findings about the role of miR-93 in breast cancer. Based on the results of this study, miR-93-5p blocks both STAT3 and megakaryoblastic leukemia/myocardin-like 1 (MLK-1) as important regulators of cellular metabolism to suppress EMT resulting in reduced migration of breast cancer cells [201]. WNK lysine deficient protein kinase 1 (WNK1) is ubiquitously expressed in all tissues essential 
for embryogenesis [202-204]. WNK1 is capable of regulation of angiogenesis, cell proliferation and cell survival via targeting various pathways such as Smad/Tgfb, Erk5/ MAPK and PI3K [205-207], demonstrating the potential role of WNK1 in tumorigenesis. By inhibition of WNK1, miR-93 diminishes the migratory capability and invasion potential of tumor cells [208].

\section{Gastric cancer}

Gastric cancer [209] is a malignant cancer with high prevalence worldwide that has higher incidence rate in Asia and Western countries [210-213]. MiR-93 can function as a biomarker for GC diagnosis since its expression undergoes upregulation during the metastasis of GC cells into lymph node [214]. A variety of molecular pathways have been recognized as determining factors in GC progression. Hippo signaling pathway is suggested to be involvement in modulation of a number of physiological and pathological mechanisms including organ development, tissue regeneration and tumor suppression [215-217]. In respect to the role of Hippo signaling pathway in regulation of cell proliferation and apoptosis, this pathway exerts anti-tumor activity [218]. The effect of Hippo pathway dysregulation on the metastasis and invasiveness of tumor cells have been detected [219]. Epigenetic alterations are responsible for inhibition of MST1/2 and large tumor suppressors 2 (LATS1/2) as vital components of Hippo pathway during GC development [220]. Besides, protocadherin Fat4 (FAT4) is a main regulator of Hippo pathway that undergoes mutation in GC cells to ensure their proliferation and viability [221]. It is held that Hippo signaling pathway is one of the potential targets of miR-93-5p. Based on the oncogenesis effect of this miR on GC cells, it was found that during GC progression, upregulation occurs in the expression of miR-93-5p to suppress Hippo pathway via down-regulation of FAT4 and LATS2 leading to the enhanced migration and invasiveness of these malignant cells [222]. However, another study conducted by Meng and colleagues provides contrast results about the effect of miR-93 on Hippo signaling pathway. This study explains that miR-93-5p is able to promote the proliferation, migration and invasiveness of GC cells by stimulation of Hippo signaling pathway [223]. As it was mentioned, abnormal expression of JAK/STAT signaling pathway considerably elevates the malignancy of cancer cells [224, 225]. At the case of GC, a similar story occurs and miR-93 activates STAT3 signaling pathway to enhance GC metastasis [226]. However, it seems that this effect of miR-93 on STAT pathway is mediated by another target. Type I interferon (IFN1) has been reported to have anti-tumor activity [227]. IFN-1 reduces the activity of STAT3 by binding to the type-I interferon receptor 1 (IFNAR1) [228-230]. By inhibition of
IFNAR1, miR-93-5p stimulates STAT3 signaling pathway to increase the malignancy and invasion of tumor cells [226]. On the other hand, lncRNA PTENP1 enhances the expression of PTEN (a tumor suppressor) to inhibit the proliferation and viability of GC cells. It seems that the stimulatory impact of lncRNA PTENP1 on PTEN is mediated by inhibition of miR-93 [231]. As it was mentioned, PDCD4 diminishes the viability and proliferation of tumor cells by stimulation of programmed cell death. The oncogenesis impact of miR-93 on GC cells is partially mediated through suppressing PDCD4 [232].

\section{Uterine cancer}

Uterine cancer is one of the most common disorders of female reproductive system [233]. Obesity and bad lifestyles are the major risk factors of uterine cancer [234]. Based on the statistics of WHO, uterine cancer claims the fourth place among women's cancer [152]. Abnormal expression of miR-93 occurs in patients with uterine cancer. These patients have a low expression of serum miR93 and its expression has an intimate relationship with pathological staging and lymph node metastasis. High expression of miR-93 is associated with good prognosis and high survival rate of patients with uterine cancer [235].

\section{Adenoid cystic carcinoma}

The primary lacrimal gland tumors have not high prevalence [236]. Adenoid cystic carcinoma (ACC) is suggested to be the most common form of malignant epithelial lacrimal gland tumors [237-239]. Radiotherapy and chemotherapy are the most frequent treatments of ACC [240, 241]. However, we have not witnessed a huge decrease in its eradication and recurrence. So, genetic manipulation is of interest in its treatment. The expression of miR-93 is higher in ACC tissues compared to the healthy ones. It is held that miR-93 upregulation enhances the metastasis of these tumor cells and stimulates epithelial-to-mesenchymal transition (EMT) via increasing the level of E-cadherin and reducing the level of N-cadherin [242]. Breast cancer metastasis suppressor 1 (BRMS1) has an intimate relationship with metastasis. Notably, BRMS1 exerts an inhibitory impact on the tumor cells by enhancing the expression of oncosuppresor miRs including miR-146a, $-146 \mathrm{~b}$ and -335 [243-246]. In the case of ACC, there is a reverse relationship between miR-93 and BRMS1L. Upregulation of miR-93 considerably diminishes the expression of BRMS1L to promote the malignancy and proliferation of cancer cells [242].

\section{Pancreatic cancer}

Pancreatic ductal adenocarcinoma still has a high mortality and morbidity worldwide demanding novel strategies 
in its treatment [247-249]. Unfortunately, this kind of cancer is usually diagnosed at the advanced stages due to its special location and lack of sensitive approaches in its diagnosis [250]. Hence, studies should focus on treatment of this life threatening disorder at the end stages. In respect to the flexibility and complexity of cancer, targeting molecular pathway is the most important strategy. Runt-related transcription factor (RUNX) is a vital gene involved in progression of pancreatic cancer cells. Expression analysis shows the high expression of RUNX2 in pancreatic cancer tissues, while its expression is at the minimal level in healthy tissues [251]. Besides, it has been reported that RUNX3 contributes to the metastasis and migration of pancreatic cancer cells [252, 253]. A same story occurs for RUNX1, so that its expression undergoes upregulation in pancreatic tumor cells associated with poor prognosis and high malignancy of pancreatic tumor cells [254-257]. These studies highlight this fact that RUNX genes have a potential in cancer progression. Interestingly, it seems that RUNX1 exerts its stimulatory impact on the migration and malignancy of pancreatic cancer cells by inhibition of miR-93 since the overexpression of miR-93 diminishes the migration and invasiveness of pancreatic cancer cells [258].

\section{Renal carcinoma}

Clear cell renal cell carcinoma (ccRCC) is the most frequent type of renal carcinoma affecting a high population of men and women around the world. Although surgery is a common option in treatment of ccRCC, it seems that patients demonstrate recurrence and metastasis after surgical resection with low survival rate [259-262]. This has resulted the willingness of scientists into other treatment options and it appears that anti-angiogenic agents are the most promising candidates. These agents can suppress the progression and malignancy of tumor cells with high capability [263-265]. Pigment epithelium derived factor (PEDF) has great anti-angiogenic activity beneficial in cancer therapy [266, 267]. It is held that miR-93-3p enhances the malignancy of ccRCC cells by stimulation of angiogenesis through down-regulation of PEDF [209]. Although it has been shown that TGF- $\beta$ contributes to the induction of cell cycle arrest, accumulating data demonstrates that the resistance of cancer cells into TGF- $\beta$ reverses its anti-tumor impact and this signaling pathway may enhance the progression of tumor cells [268-272]. The fundamental pathway involved in this function is various among different cancer types [273]. Mutations or deletions in Smad4 are responsible for promoting the progression of pancreatic cancer cells resistant to TGF- $\beta$ [274]. However, TGF- $\beta$ regulates an important axis in renal carcinoma cells that eventually reduces the proliferation of these malignant cells. It is held that TGF- $\beta$ upregulation significantly diminishes the expression of miR-93 that in turn, stimulates RBL2 leading to the cell cycle arrest [275].

\section{Bladder cancer}

Bladder carcinoma (BC) is supposed to be one of the malignant tumors of the urinary tract. In spite of the good prognosis of patients with $\mathrm{BC}$, its incidence rate is still high [276]. Currently, Bacillus Calmette-Guerin is the best option for the treatment of BC [277]. Moreover, transurethral resectioning and chemotherapy are beneficial in BC therapy [278-280]. However, the resistance of $\mathrm{BC}$ cells remarkably reduces the potential of chemotherapy [281, 282]. Increasing evidence suggests that abnormal expression of miRs is an important factor in BC metastasis and progression $[283,284]$. It seems that inhibition of miR-93 is advantageous in enhancing the anti-tumor activity of cisplatin (CS) against BC cells via stimulation of DNA damage [285]. LASS2 exerts inhibitory impact on BC cells and involves in chemo-sensitization [286]. It has been demonstrated that miR-93 induces the resistance of $\mathrm{BC}$ cells into chemotherapy by inhibition of LASS2 protein [285].

\section{Ovarian cancer}

Ovarian cancer is a gynecological malignancy affecting a high population of women around the world with low 5 -survival rate [287, 288]. Unfortunately, there are no advanced and sensitive tools for early diagnosis of ovarian cancer [289, 290]. So, treatment should be focused on using chemotherapeutic agents. In spite of the efficiency of chemotherapy, frequent application of these agents significantly reduces their capability in cancer therapy [291, 292]. As a consequence, scientists have had a special view into plant-derived natural products as agents with high anti-tumor activity that can be applied as adjuvant in cancer therapy [293-295]. Berberine (Brb) is a naturally occurring compound exclusively found in the members of Berberis family with high concentration in Berberis vulgaris [296]. This compound has a number of pharmacological activities such as antioxidant, antiinflammatory, anti-diabetic and anti-tumor [297]. A combination of Brb and cisplatin significantly sensitizes ovarian cancer cells into apoptotic cell death and cell cycle arrest by inhibition of miR-93 and consequently, stimulation of PTEN/Akt axis [298]. MiR-93 down-regulation is a potent biomarker of ovarian cancer with the sensitivity as much as 93\% [299].

\section{Colorectal cancer}

Colorectal cancer (CRC) is considered as the third leading cause of death [300]. This life threatening disorder has high metastasis capability and there have been attempts 
to evaluate the molecular signaling pathways involved in its progression [301, 302]. It is held that IncRNA CA3AS1 is capable of reducing the malignancy of colorectal cancer cells by inhibition of miR-93 and consequently, induction of PTEN as a tumor suppressor [303].

\section{MiR-93 and angiogenesis}

Angiogenesis is one of the most important mechanisms involved in delivering oxygen and nutrients to the tumor cells [304]. It seems that this mechanism plays a remarkable role in a variety of stages of cancer such as proliferation and migration [305]. Anti-angiogenic agents have demonstrated great potential in inhibition of malignancy and invasion of cancer cells [306, 307]. There are two major problems associated with inhibition of angiogenesis: A) it appears that the introduced anti-angiogenic drugs are capable of suppressing angiogenesis in a just a number of cancers, and B) some of the tumor cells are able to advance without angiogenesis enhancing the complexity of cancer [308]. So, elucidating the molecular pathways involved in angiogenesis is suggested to be beneficial in cancer therapy. Upregulation of miR-93-5p increases the angiogenesis capability of human umbilical vein endothelial cells (HUVECs) leading to the improvement in blood vessel density, high proliferation and migration, and enhanced lumen formation and sprouting [309]. The interesting point of this study is the role of molecular signaling pathways. Epithelial protein lost in neoplasm (EPLIN) is a cytoskeleton-associated protein that plays a significant role in supervising the cell motility and actin dynamics. It has been demonstrated that high expression of EPLIN is related to the reduced ability of HUVECs in migration and tubule formation [310]. As a consequence, based on the efficiency of miR-93-5p in enhancing the angiogenesis and cell motility of HUVECs, it seems that this miR exerts inhibitory impact on EPLIN [309].

\section{Conclusion and remarks}

This review provided a comprehensive discussion about the role of miR-93 in various cancer cell lines. Notably, all the studies conducted on the expression of miR93 in lung cancer demonstrate that its upregulation is associated with poor prognosis of patients with lung cancer. More importantly, these studies imply that miR93 is an oncogenesis $\mathrm{miR}$ in lung cancer that favors conditions into high proliferation and viability of lung cancer cells. The same story occurs in EC cancer. This miR not only serves as a biomarker during EC generation but also enhances the malignancy of cancer cells by inhibition of PTEN/PI3K/Akt signaling pathway. MiR-93/FZD7/Wnt axis is also important for promoting the progression of OS cells. It is noteworthy that the studies involving in the role of miR-93 in EC, OS and

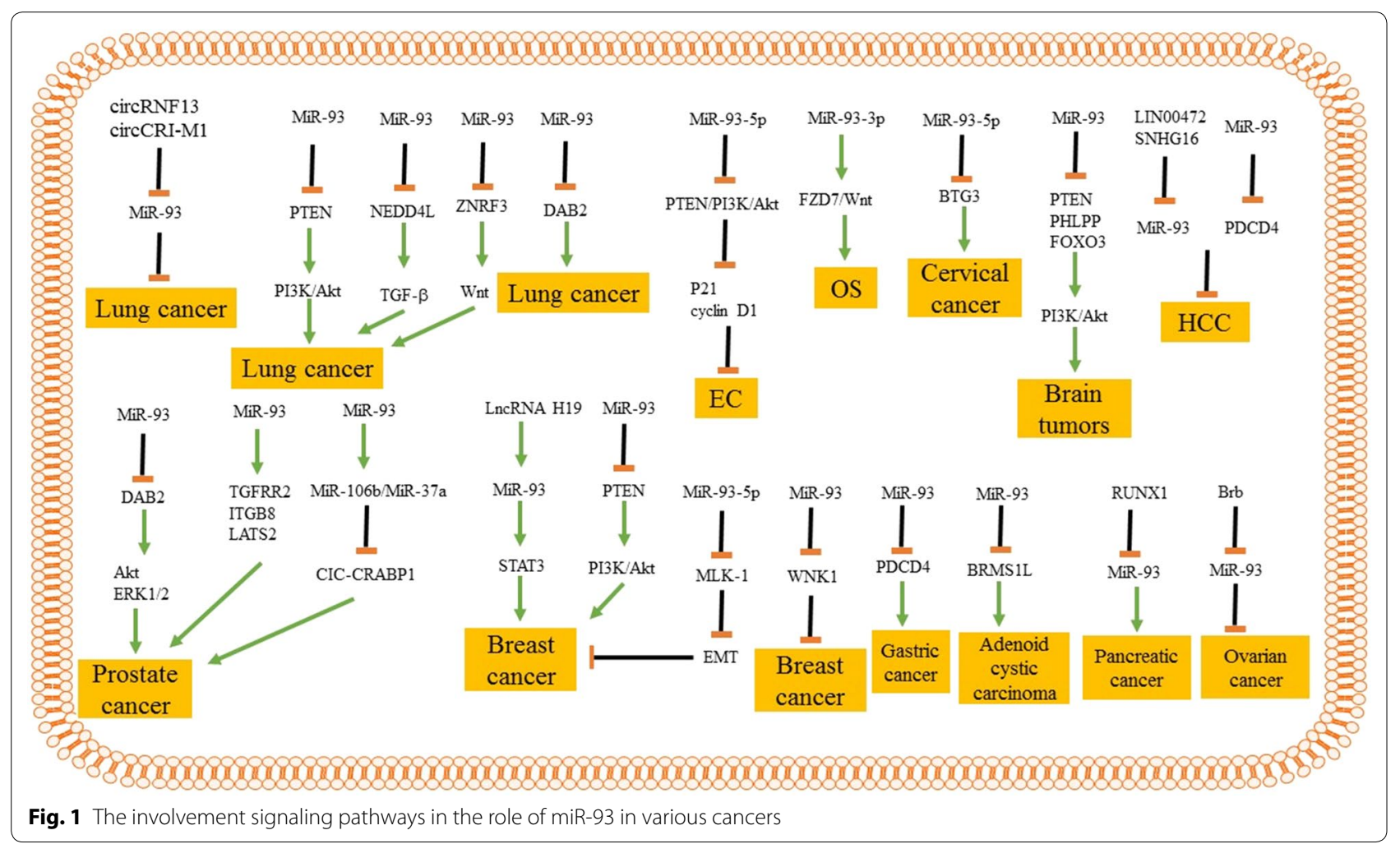


cervical cancers are low in number and more studies are required to clarify the oncogenesis or oncosuppressor impact of miR-93. But these experiments highlight the oncogenesis impact of miR-93. Interestingly, accumulating data demonstrates that miR-93 indirectly stimulates PI3K/Akt pathway to elevate the proliferation and malignancy of brain tumors. In this way, miR-93 suppresses the expression of PTEN, PHLPP, and FOXO3. It seems that miR-93 affects much more molecular pathways in prostate cancer. Figure 1 obviously shows these pathways. LncRNAs play a significant role in suppressing HCC. LncRNAs SNHG16 and LINC00472 exert inhibitory impact on the progression of HCC cells by down-regulation of miR-93. Investigating the role of miR-93 elucidated two major downstream targets known as STAT3 and WNK1. These two pathways are involved in regulation of a number of biological processes. MiR-93 suppresses WNK1 to reduce breast cancer malignancy, while it enhances the expression of STAT3. Figure 1 demonstrates the signaling pathways involved in the effect of miR-93 on various cancers. Besides, miR-93 is able to affect angiogenesis in cancer progression. MiR-93 reduces the expression of EPLIN to enhance angiogenesis. Finally, there is more studies that are supporting the role of miR-93 in cancer therapy [311-325], Table 1.

Table 1 The studies supporting the involvement of miR-93 in cancer malignancy

\begin{tabular}{|c|c|c|c|}
\hline In vitro/in vivo & Effect on cancer & Major results & Refs. \\
\hline Glioblastoma cells & Oncogenesis & $\begin{array}{l}\text { MiR-93 enhances the malignancy and proliferation of glioblastoma cells } \\
\text { by inhibition of autophagy via down-regulation of Beclin-1, ATG5, and } \\
\text { ATG4B }\end{array}$ & [106] \\
\hline EC cells & Oncogenesis & Reducing the capability of radiotherapy by inhibition of BTG3 & [125] \\
\hline HeLa and C-33A cells cervical cancer tissues & Oncogenesis & $\begin{array}{l}\text { LncRNA ZNF667 suppresses the invasion and malignancy of cancer cells by } \\
\text { inhibition of miR-93-3p }\end{array}$ & [311] \\
\hline Cisplatin-resistant A2780/DDP cell line & Oncogenesis & $\begin{array}{l}\text { Inhibition of miR-93 by L-tetrahydropalmatine is beneficial in sensitizing of } \\
\text { cancer cells to cisplatin-mediated apoptosis }\end{array}$ & [312] \\
\hline Bladder cancer tissues and cells & Oncogenesis & $\begin{array}{l}\text { Upregulation of miR-93 is related to the tumor stage and node stage via } \\
\text { stimulation of PEDF }\end{array}$ & [313] \\
\hline $\begin{array}{l}\text { Cervical cancer and matched non-cancerous } \\
\text { tissue samples }\end{array}$ & Oncogenesis & $\begin{array}{l}\text { Overexpression of miR-93 and inhibition of CDKN1A is associated with poor } \\
\text { prognosis of patients }\end{array}$ & [314] \\
\hline Gastric cancer cells & Oncogenesis & $\begin{array}{l}\text { By inhibition of TIMP2, miR-93 enhances the malignancy of gastric cancer } \\
\text { cells }\end{array}$ & [315] \\
\hline Primary colon cancer cells & Oncogenesis & $\begin{array}{l}\text { By inhibition of miR-93, IncRNA LINC01567 reduces the proliferation an } \\
\text { malignancy of cancer cells }\end{array}$ & [316] \\
\hline $\begin{array}{l}\text { Endometrial carcinoma tissues endometrial } \\
\text { carcinoma cell lines HEC-1B and Ishikawa }\end{array}$ & Oncogenesis & $\begin{array}{l}\text { Enhancing the proliferation and malignancy of tumor cells by stimulation } \\
\text { of EMT }\end{array}$ & [317] \\
\hline $\begin{array}{l}\text { Ovarian carcinoma cell lines OVCAR3, SKOV3/ } \\
\text { DDP, and HO8910-PM }\end{array}$ & Oncogenesis & $\begin{array}{l}\text { MiR-93-5p down-regulates the expression of RhoC to elevate the invasive- } \\
\text { ness of cancer cells }\end{array}$ & [318] \\
\hline $\begin{array}{l}\text { Human colon cancer tissue and colorectal } \\
\text { carcinoma cell lines }\end{array}$ & Oncosuppressor & $\begin{array}{l}\text { Diminishing the malignancy and migration of cancer cells by inhibition of } \\
\text { Wnt signaling pathway }\end{array}$ & [319] \\
\hline Hep-2 cells cancer tissues & Oncogenesis & $\begin{array}{l}\text { MiR-93 binds to the } 3^{\prime} \text {-UTR of cyclin G2 to inhibit its expression resulting in } \\
\text { promoted proliferation of cancer cells }\end{array}$ & [320] \\
\hline Breast cancer tissues & Oncogenesis & Overexpression of miR-93 occurs in triple negative breast cancer & [321] \\
\hline Rat model of mammary carcinogenesis & Oncogenesis & $\begin{array}{l}\text { Upregulated miR- } 93 \text { suppresses the expression of } \mathrm{Nrf2} \text { to enhance the } \\
\text { tumorigenesis of breast cancer cells }\end{array}$ & [322] \\
\hline Tumoral and nontumoral colon tissues & Oncosuppressor & A decrease occurs in the expression of miR-93 in colon cancer cells & [323] \\
\hline $\begin{array}{l}\text { Early (recurrence within } 12 \text { months after } \\
\text { surgery) and non-early relapse CRC patients } \\
\text { CRC cells }\end{array}$ & Oncosuppressor & $\begin{array}{l}\text { Reducing the progression and growth of cancer cells down-regulation of } \\
\text { VEGF, p21 and ERBB2 }\end{array}$ & [324] \\
\hline Cisplatin-resistant ovarian cancer cells & Oncosuppressor & $\begin{array}{l}\text { Upregulation of miR-93 reduces the expression of PTEN to stimulate Akt } \\
\text { signaling pathway leading to the sensitization of cancer cells to chemo- } \\
\text { therapy }\end{array}$ & [325] \\
\hline
\end{tabular}




\begin{abstract}
Abbreviations
5-FU: 5-Fluorouracil; Ago: Argonaute; Brb: Berberine; BC: Bladder carcinoma; BRMS1: Breast cancer metastasis suppressor 1; circRNAs: Circular RNAs; CS: Cisplatin; ccRCC: Clear cell renal cell carcinoma; CRC: Colorectal cancer; DAB2: Disabled homolog 2; DAB2: Disabled homolog 2; DOX: Doxorubicin; DCIS: Ductal carcinoma in situ; EPLIN: Epithelial protein lost in neoplasm; EMT: Epithelial-to-mesenchymal transition; Nrf2: Erythroid 2-related factor 2; Exp5: Exportin-5; FOXO3: Forkhead box O3; GPR137C: G-protein coupled receptor 137C; HCC: Hepatocellular carcinoma cell; HUVECs: Human umbilical vein endothelial cells; LATS1/2: Large tumor suppressors 2; IncRNAs: Long non-coding RNAs; MLK-1: Megakaryoblastic leukemia/myocardin-like 1; miRs: MicroRNAs; miRISC: miR-induced silencing complex; MAPK2: Mitogen-activated protein kinase 2; NEDD4L: Neural precursor cell expressed developmentally downregulated gene 4-like; NDs: Neurological disorders; NSCLC: Non-small cell lung cancer; PPARGC1A: Peroxisome proliferator-activated receptor gamma coactivator-1 alpha; P-gp: P-glycoprotein; PHLPP: PH domain leucine rich repeat protein phosphatases; PEDF: Pigment epithelium derived factor; PCNSL: Primary central nervous system lymphoma; pri-miR: PrimarymiR; PDCD1LG2: Programmed cell death 1 ligand 2; PDCD4: Programmed cell death 4; TRBP: RNA-binding protein; RUNX: Runt-related transcription factor: STAT3: Signal transducer and activator of transcription $3 ;$ TGF- $\beta$ : Tumor growth factor- $\beta$; WNK1:WNK lysine deficient protein kinase 1; WHO: World Health Organization; ZNRF3: Zinc and ring finger 3.
\end{abstract}

\section{Acknowledgements}

Not applicable.

\section{Authors' contributions}

Study conception and design: SS and MA. Acquisition of data: MNRM and TF. Drafting of the manuscript: SS, MA and MN. Critical revision: SS. All authors read and approved the final manuscript.

\section{Funding}

There is no funding source.

\section{Availability of supporting data}

The data sets supporting the results of this article are included within the article.

\section{Ethics approval and consent to participate}

Not applicable.

\section{Consent for publication}

The author give full permission to publish the relevant contribution.

\section{Competing interests}

The authors declare that they have no competing interests.

\section{Author details}

${ }^{1}$ Department of Basic Science, Faculty of Veterinary Medicine, University of Tabriz, Tabriz, Iran. ${ }^{2}$ Radiology and Nuclear Medicine Department, School of Paramedical Sciences, Kermanshah University of Medical Sciences, Kermanshah, Iran. ${ }^{3}$ Pharmaceutics Research Center, Institute of Neuropharmacology, Kerman University of Medical Sciences, Kerman, Iran. ${ }^{4}$ Cardiovascular Diseases Research Center, Birjand University of Medical Sciences, Birjand, Iran ${ }^{5}$ Healthy Ageing Research Center, Neyshabur University of Medical Sciences, Neyshabur, Iran.

Received: 15 November 2019 Accepted: 15 June 2020

Published online: 29 June 2020

\section{References}

1. Ghizoni J, et al. The utilization of saliva as an early diagnostic tool for oral cancer: microRNA as a biomarker. Clin Transl Oncol. 2020;22:804-12.

2. Ashrafizadeh $M$, et al. Nanoparticles targeting STATs in cancer therapy. Cells. 2019;8(10):1158.

3. Tavakol S, et al. Autophagy modulators: mechanistic aspects and drug delivery systems. Biomolecules. 2019;9(10):530.
4. Mohammadinejad R, et al. Berberine as a potential autophagy modulator. J Cell Physiol. 2019. https://doi.org/10.1002/jcp.28325.

5. Rivera C. Essentials of oral cancer. Int J Clin Exp Pathol. 2015;8(9):11884.

6. Ashrafizadeh $M$, et al. Autophagy, anoikis, ferroptosis, necroptosis, and endoplasmic reticulum stress: potential applications in melanoma therapy. J Cell Physiol. 2019;234:19471-9.

7. Ringash J, et al. Outcomes toolbox for head and neck cancer research. Head Neck. 2015:37(3):425-39.

8. Riley P. et al. Interventions for preventing oral mucositis in patients with cancer receiving treatment: oral cryotherapy. Cochrane Database Syst Rev. 2015(12):CD011552. https://doi.org/10.1002/14651858.

9. Zhu M, et al. MicroRNA-139-5p regulates chronic inflammation by suppressing nuclear factor-kappaB activity to inhibit cell proliferation and invasion in colorectal cancer. Exp Ther Med. 2019;18(5):4049-57.

10. Wang SY, et al. High expression of MicroRNA-196a is associated with progression of hepatocellular carcinoma in younger patients. Cancers. 2019;11(10):1549.

11. Ding ZS, et al. MicroRNA-34a inhibits bladder cancer cell migration and invasion, and upregulates PTEN expression. Oncol Lett. 2019;18(5):5549-54.

12. Rawat $M$, et al. MicroRNA in pancreatic cancer: from biology to therapeutic potential. Genes. 2019;10(10):752.

13. Lee $S W L$, et al. MicroRNA delivery through nanoparticles. J Control Release. 2019:313:80-95.

14. Ashrafizadeh $\mathrm{M}$, et al. MicroRNAs mediate the anti-tumor and protective effects of ginsenosides. Nutr Cancer. 2019. https://doi. org/10.1080/01635581.2019.1675722.

15. Lee RC, Feinbaum RL, Ambros V. The C. elegans heterochronic gene lin-4 encodes small RNAs with antisense complementarity to lin-14. Cell. 1993;75(5):843-54.

16. Kozomara A, Griffiths-Jones S. miRBase: annotating high confidence microRNAs using deep sequencing data. Nucleic Acids Res. 2013;42(D1):D68-73.

17. Malczewska A, et al. A comprehensive assessment of the role of miRNAs as biomarkers in gastroenteropancreatic neuroendocrine tumors. Neuroendocrinology. 2018;107:73-90.

18. Chiu CC, et al. Upregulated expression of microRNA-204-5p leads to the death of dopaminergic cells by targeting DYRK1A-mediated apoptotic signaling cascade. Front Cell Neurosci. 2019;13:399.

19. Yan $L$, et al. Inhibition of microRNA-21-5p reduces keloid fibroblast autophagy and migration by targeting PTEN after electron beam irradiation. Lab Invest. 2020;100:387-99.

20. Zan T, et al. Downregulation of microRNA-124 prevents the development of acute liver failure through the upregulation of PIM-3. Exp Physiol. 2020;105:108-19.

21. Song W, et al. Overexpression of IncRNA PIK3CD-AS1 promotes expression of LATS1 by competitive binding with microRNA-566 to inhibit the growth, invasion and metastasis of hepatocellular carcinoma cells. Cancer Cell Int. 2019;19:150.

22. Shi Y, et al. MicroRNA-219a-5p suppresses intestinal inflammation through inhibiting Th1/Th17-mediated immune responses in inflammatory bowel disease. Mucosal Immunol. 2020;13:303-12.

23. Huang K, et al. Upregulated microRNA-106a promotes porcine preadipocyte proliferation and differentiation by targeting different genes. Genes. 2019;10(10):805.

24. Guo Y, et al. MicroRNA-15a inhibits glucose transporter 4 translocation and impairs glucose metabolism in 16 skeletal muscle via targeting of vesicle-associated membrane protein-associated protein A. Can $J$ Diabetes. 2020;44(3):261-6.

25. Ambros $V$. The functions of animal microRNAs. Nature. 2004:431(7006):350

26. Bartel DP. MicroRNAs: genomics, biogenesis, mechanism, and function. Cell. 2004;116(2):281-97.

27. Wang $\mathrm{H}$, et al. Multiple roles of microRNA-146a in immune responses and hepatocellular carcinoma. Oncol Lett. 2019;18(5):5033-42.

28. Xu W, et al. Inhibitory effect of microRNA-608 on lung cancer cell proliferation, migration, and invasion by targeting BRD4 through the JAK2/ STAT3 pathway. Bosn J Basic Med Sci. 2019. https://doi.org/10.17305/ bjbms.2019.4216. 
29. Hua YQ, et al. Long non-coding SBF2-AS1 acting as a competing endogenous RNA to sponge microRNA-142-3p to participate in gemcitabine resistance in pancreatic cancer via upregulating TWF1. Aging. 2019;11:5579.

30. Song $X$, et al. Matrix stiffening induces endothelial dysfunction via the TRPV4/microRNA-6740/ET-1 mechanotransduction pathway. Acta Biomater. 2019;100:52-60.

31. Wang $L$, et al. Role of cardiac progenitor cell-derived exosomemediated microRNA-210 in cardiovascular disease. J Cell Mol Med. 2019;23(7124):7131.

32. Shang Y, et al. MicroRNA-93 regulates the neurological function, cerebral edema and neuronal apoptosis of rats with intracerebral hemorrhage through TLR4/NF-kappaB signaling pathway. Cell Cycle. 2019;18(22):3160-76.

33. Sun L, Ji S, Xing J. Inhibition of microRNA-155 alleviates neurological deficits following transient global ischemia and contribution of neuroinflammation and oxidative stress in the hippocampus. Curr Pharm Des. 2019;25:4310-7.

34. Chen $L$, et al. Upregulation of microRNA-141 contributes to suppressing epithelial-mesenchymal transition and lymph node metastasis in laryngeal cancer through HOXC6-dependent TGF-beta signaling pathway. Cell Signal. 2019;66:109444.

35. Yu Y, et al. MicroRNA-132 suppresses migration and invasion of renal carcinoma cells. J Clin Lab Anal. 2019;34:e22969.

36. Fu Q, et al. microRNA-29b inhibits cell growth and promotes sensitivity to oxaliplatin in colon cancer by targeting FOLR1. BioFactors. 2019:46:136-45.

37. Lee $Y$, et al. MicroRNA maturation: stepwise processing and subcellular localization. EMBO J. 2002;21(17):4663-70.

38. Denli AM, et al. Processing of primary microRNAs by the Microprocessor complex. Nature. 2004;432(7014):231.

39. Schwarz DS, et al. Asymmetry in the assembly of the RNAi enzyme complex. Cell. 2003;115(2):199-208.

40. Cosentino G, et al. MicroRNA and oxidative stress interplay in the context of breast cancer pathogenesis. Int J Mol Sci. 2019;20(20):5143.

41. Rios-Colon L, Deep G, Kumar D. Emerging role of microRNA 628$5 p$ as a novel biomarker for cancer and other diseases. Tumor Biol. 2019;41(10):1010428319881344.

42. Soleimani $A$, et al. Role of the transforming growth factor- $\beta$ signaling pathway in the pathogenesis of colorectal cancer. J Cell Biochem. 2019;120(6):8899-907.

43. Zhao Z, et al. microRNA-132 inhibits cardiomyocyte apoptosis and myocardial remodeling in myocardial infarction by targeting IL-1 beta. J Cell Physiol. 2020;235(3):2710-21.

44. Tang $Y$, et al. Inhibition of microRNA-875-5p promotes radioiodine uptake in poorly differentiated thyroid carcinoma cells by upregulating sodium-iodide symporter. J Endocrinol Invest. 2020;43(4):439-50.

45. Xiang $X$, et al. Everolimus inhibits the proliferation and migration of epidermal growth factor receptor-resistant lung cancer cells A549 via regulating the microRNA-4328/phosphatase and tensin homolog signaling pathway. Oncol Lett. 2019;18(5):5269-76.

46. Li D, et al. Long non-coding RNA GATA6-AS inhibits gastric cancer cell proliferation by downregulating microRNA-25-3p. Oncol Lett. 2019;18(5):4639-44

47. Chen C. et al. Circular RNA Pleiotrophin promotes carcinogenesis in glioma via regulation of microRNA-122/SRY-box transcription factor 6 axis. Eur J Cancer Prev. 2019.

48. Zhao W, et al. MicroRNA-152 suppresses cisplatin resistance in A549 cells. Oncol Lett. 2019;18(5):4613-20.

49. Takeno T, et al. MicroRNA-205-5p inhibits three-dimensional spheroid proliferation of ErbB2-overexpressing breast epithelial cells through direct targeting of CLCN3. PeerJ. 2019;7:e7799.

50. Tang $X$, et al. MicroRNA-215-3p suppresses the growth, migration, and invasion of colorectal cancer by targeting FOXM1. Technol Cancer Res Treat. 2019;18:1533033819874776.

51. Meng F, et al. MicroRNA-877 is downregulated in cervical cancer and directly targets MACC 1 to inhibit cell proliferation and invasion. Exp Ther Med. 2019;18(5):3650-8.

52. Hsiao K-Y, et al. Noncoding effects of circular RNA CCDC66 promote colon cancer growth and metastasis. Cancer Res. 2017;77(9):2339-50.
53. Ma Q, et al. Blood microRNA-93 as an indicator for diagnosis and prediction of functional recovery of acute stroke patients. J Clin Neurosci. 2019:62:121-7.

54. Lei $\mathrm{P}$, et al. Microarray based analysis of microRNA expression in rat cerebral cortex after traumatic brain injury. Brain Res. 2009;1284:191-201.

55. Hu Z, et al. Expression of miRNAs and their cooperative regulation of the pathophysiology in traumatic brain injury. PLoS ONE. 2012;7(6):e39357.

56. Yang T, et al. Elevated serum miR-93, miR-191, and miR-499 are noninvasive biomarkers for the presence and progression of traumatic brain injury. J Neurochem. 2016;137(1):122-9.

57. Dharap A, et al. Transient focal ischemia induces extensive temporal changes in rat cerebral microRNAome. J Cereb Blood Flow Metab. 2009;29(4):675-87.

58. Wang $\mathrm{P}$, et al. MicroRNA-93 downregulation ameliorates cerebral ischemic injury through the $\mathrm{Nrf2/HO}-1$ defense pathway. Neurochem Res. 2016;41(10):2627-35.

59. Ralfkiaer $U$, et al. MicroRNA expression in early mycosis fungoides is distinctly different from atopic dermatitis and advanced cutaneous T-cell lymphoma. Anticancer Res. 2014;34(12):7207-17.

60. Fabbri $\mathrm{E}$, et al. Regulation of IL-8 gene expression in gliomas by microRNA miR-93. BMC Cancer. 2015;15(1):661.

61. Yan X-T, et al. MicroRNA-93 alleviates neuropathic pain through targeting signal transducer and activator of transcription 3. Int Immunopharmacol. 2017:46:156-62.

62. Anupam $\mathrm{K}$, et al. Loss of disabled-2 expression is an early event in esophageal squamous tumorigenesis. World J Gastroenterol. 2006;12(37):6041

63. Elavarasu S, et al. Evaluation of superoxide dismutase levels in local drug delivery system containing $0.2 \%$ curcumin strip as an adjunct to scaling and root planing in chronic periodontitis: a clinical and biochemical study. J Pharm Bioallied Sci. 2016;8(Suppl 1):S48.

64. Ganta VC, et al. A microRNA93-interferon regulatory factor-9-immunoresponsive gene-1-itaconic acid pathway modulates M2-like macrophage polarization to revascularize ischemic muscle. Circulation. 2017;135(24):2403-25.

65. Zhang J, et al. Curcumin improves perfusion recovery in experimental peripheral arterial disease by upregulating microRNA-93 expression. Exp Therap Med. 2019;17(1):798-802.

66. Yang J, et al. Silencing of long noncoding RNA XIST protects against renal interstitial fibrosis in diabetic nephropathy via microRNA93-5p-mediated inhibition of CDKN1A. Am J Physiol Renal Physiol. 2019;317:1350-8

67. Samarghandian S, et al. Thymoquinone-induced antitumor and apoptosis in human lung adenocarcinoma cells. J Cell Physiol. 2019;234(7):10421-31.

68. Samarghandian S, et al. Role of caspases, Bax and Bcl-2 in chrysininduced apoptosis in the A549 human lung adenocarcinoma epithelial cells. Anticancer Agents Med Chem. 2014;14(6):901-9.

69. Meng Y-B, et al. Long noncoding RNA CRNDE promotes multiple myeloma cell growth by suppressing miR-451. Oncol Res Feat Preclin Clin Cancer Ther. 2017;25(7):1207-14.

70. Chen J, et al. Circular RNA profile identifies circPVT1 as a proliferative factor and prognostic marker in gastric cancer. Cancer Lett. 2017:388:208-19.

71. Memczak S, et al. Circular RNAs are a large class of animal RNAs with regulatory potency. Nature. 2013;495(7441):333.

72. Qu S, et al. Circular RNA: a new star of noncoding RNAs. Cancer Lett. 2015;365(2):141-8.

73. Zhao Z-J, Shen J. Circular RNA participates in the carcinogenesis and the malignant behavior of cancer. RNA Biol. 2017;14(5):514-21.

74. Li Z, et al. Exon-intron circular RNAs regulate transcription in the nucleus. Nat Struct Mol Biol. 2015;22(3):256.

75. Salmena $L$, et al. A ceRNA hypothesis: the Rosetta Stone of a hidden RNA language? Cell. 2011;146(3):353-8.

76. Jeck WR, Sharpless NE. Detecting and characterizing circular RNAs. Nat Biotechnol. 2014;32(5):453.

77. Jiang $\mathrm{L}-\mathrm{H}$, et al. CircRNA: a novel type of biomarker for cancer. Breast Cancer. 2018:25(1):1-7. 
78. Burd CE, et al. Expression of linear and novel circular forms of an INK4/ ARF-associated non-coding RNA correlates with atherosclerosis risk. PLoS Genet. 2010;6(12):e1001233.

79. Ghosal S, et al. Circ2Traits: a comprehensive database for circular RNA potentially associated with disease and traits. Front Genet. 2013;4:283.

80. Wang L, et al. Circular RNA circCRIM1 inhibits invasion and metastasis in lung adenocarcinoma through the microRNA (miR)-182/miR-93-leukemia inhibitory factor receptor pathway. Cancer Sci. 2019;110(9):2960.

81. Wang $L$, et al. CircRNF13 regulates the invasion and metastasis in lung adenocarcinoma by targeting miR-93-5p. Gene. 2018;671:170-7.

82. Subramaniam S, et al. Lung cancer biomarkers: state of the art. J Carcinog. 2013;12:3. https://doi.org/10.4103/1477-3163.107958.

83. Yang W, et al. MiR-93-5p up-regulation is involved in non-small cell lung cancer cells proliferation and migration and poor prognosis. Gene. 2018;647:13-20

84. Li C, Lyu J, Meng QH. MiR-93 promotes tumorigenesis and metastasis of non-small cell lung cancer cells by activating the PI3K/Akt pathway via inhibition of LKB1/PTEN/CDKN1A. J Cancer. 2017;8(5):870.

85. Goel P, Manning JA, Kumar S. NEDD4-2 (NEDD4L): the ubiquitin ligase for multiple membrane proteins. Gene. 2015:557(1):1-10.

86. Dahlberg J, et al. Polymorphism in NEDD4L is associated with increased salt sensitivity, reduced levels of P-renin and increased levels of $\mathrm{Nt}-$ proANP. PLOS ONE. 2007;2(5):e432.

87. Russo CJ, et al. Association of NEDD4L ubiquitin ligase with essential hypertension. Hypertension. 2005;46(3):488-91.

88. Sakashita $\mathrm{H}$, et al. Identification of the NEDD4L gene as a prognostic marker by integrated microarray analysis of copy number and gene expression profiling in non-small cell lung cancer. Ann Surg Oncol. 2013;20(3):590-8.

89. Kovacevic $Z$, et al. The iron-regulated metastasis suppressor NDRG1 targets NEDD4L, PTEN, and SMAD4 and inhibits the PI3K and Ras signaling pathways. Antioxid Redox Signal. 2013;18(8):874-87.

90. Tanksley JP, Chen X, Coffey RJ. NEDD4L is downregulated in colorectal cancer and inhibits canonical WNT signaling. PLOS ONE. 2013:8(11):e81514.

91. Gao $S$, et al. Ubiquitin ligase Nedd4L targets activated Smad2/3 to limit TGF- $\beta$ signaling. Mol Cell. 2009;36(3):457-68.

92. Qu M-H, et al. miR-93 promotes TGF- $\beta$-induced epithelial-to-mesenchymal transition through downregulation of NEDD4L in lung cancer cells. Tumor Biol. 2016;37(4):5645-51.

93. Zhao L, et al. E6-induced selective translation of WNT4 and JP2 promotes the progression of cervical cancer via a non-canonical WNT signaling pathway. Signal Transduct Target Ther. 2019;4:32.

94. Qu J, et al. Mast cells induce epithelial-to-mesenchymal transition and migration in non-small cell lung cancer through IL-8/Wnt/beta-catenin pathway. J Cancer. 2019;10(22):5567.

95. Zhou W, et al. SOX17 inhibits tumor metastasis via Wnt signaling in endometrial cancer. Onco Targets Ther. 2019;12:8275-86.

96. Zhou Y, Jin Z, Wang C. Glycogen phosphorylase B promotes ovarian cancer progression via Wnt/beta-catenin signaling and is regulated by miR-133a-3p. Biomed Pharmacother. 2019;120:109449.

97. Hao H-X, et al. ZNRF3 promotes Wnt receptor turnover in an R-spondinsensitive manner. Nature. 2012:485(7397):195.

98. Shi J, et al. ZNRF3 contributes to the growth of lung carcinoma via inhibiting Wnt/ $\beta$-catenin pathway and is regulated by miR-93. Tumor Biol. 2016;37(3):3051-7.

99. Zhu W, et al. Expression of miR-29c, miR-93, and miR-429 as potential biomarkers for detection of early stage non-small lung cancer. PLoS ONE. 2014;9(2):e87780.

100. Karam JA, et al. Decreased DOC-2/DAB2 expression in urothelial carcinoma of the bladder. Clin Cancer Res. 2007;13(15):4400-6.

101. Mok S, et al. DOC-2, a candidate tumor suppressor gene in human epithelial ovarian cancer. Oncogene. 1998;16(18):2381-7.

102. Fazili $Z$, et al. Disabled-2 inactivation is an early step in ovarian tumorigenicity. Oncogene. 1999;18(20):3104.

103. Tseng C-P, et al. Regulation of rat DOC-2 gene during castrationinduced rat ventral prostate degeneration and its growth inhibitory function in human prostatic carcinoma cells. Endocrinology. 1998;139(8):3542-53.
104. Bagadi SAR, et al. Frequent loss of Dab2 protein and infrequent promoter hypermethylation in breast cancer. Breast Cancer Res Treat. 2007;104(3):277-86.

105. Du L, et al. miR-93-directed downregulation of DAB2 defines a novel oncogenic pathway in lung cancer. Oncogene. 2014;33(34):4307-15.

106. Huang T, et al. MIR93 (microRNA-93) regulates tumorigenicity and therapy response of glioblastoma by targeting autophagy. Autophagy. 2019;15(6):1100-11.

107. Bray F, et al. Global cancer statistics 2018: GLOBOCAN estimates of incidence and mortality worldwide for 36 cancers in 185 countries. CA Cancer J Clin. 2018;68(6):394-424.

108. Khan AA, et al. Chronic exposure to cigarette smoke and chewing tobacco alters expression of microRNAs in esophageal epithelial cells. MicroRNA. 2018;7(1):28-37.

109. Dong J, et al. Determining risk of Barrett's esophagus and esophageal adenocarcinoma based on epidemiologic factors and genetic variants. Gastroenterology. 2018;154(5):1273-81.

110. Mathé EA, et al. MicroRNA expression in squamous cell carcinoma and adenocarcinoma of the esophagus: associations with survival. Clin Cancer Res. 2009:15(19):6192-200.

111. Wang Z, et al. Synthetic circular multi-miR sponge simultaneously inhibits miR-21 and miR-93 in esophageal carcinoma. Lab Investig. 2019;99(1442):1453.

112. Kong FR, et al. LncRNA PCAT6 promotes occurrence and development of ovarian cancer by inhibiting PTEN. Eur Rev Med Pharmacol Sci. 2019;23(19):8230-8.

113. Sun JF, et al. Exosome-mediated MiR-155 transfer contributes to hepatocellular carcinoma cell proliferation by targeting PTEN. Med Sci Monit Basic Res. 2019:25:218-28.

114. Liu MX, et al. miR-93-5p transferred by exosomes promotes the proliferation of esophageal cancer cells via intercellular communication by targeting PTEN. Biomed Environ Sci. 2018;31(3):171-85.

115. Ansari $\mathrm{MH}$, et al. Deregulation of miR-93 and miR-143 in human esophageal cancer. Tumor Biol. 2016;37(3):3097-103.

116. Bishop MW, Janeway KA, Gorlick R. Future directions in the treatment of osteosarcoma. Curr Opin Pediatr. 2016;28(1):26.

117. Yu X, et al. Long non-coding RNA Taurine upregulated gene 1 promotes osteosarcoma cell metastasis by mediating HIF-1a via miR-143-5p. Cell Death Dis. 2019;10(4):280.

118. Mirabello L, Troisi RJ, Savage SA. International osteosarcoma incidence patterns in children and adolescents, middle ages and elderly persons. Int J Cancer. 2009;125(1):229-34.

119. Zhu YJ, Jiang DM. LncRNA PART1 modulates chondrocyte proliferation, apoptosis, and extracellular matrix degradation in osteoarthritis via regulating miR-373-3p/SOX4 axis. Eur Rev Med Pharmacol Sci. 2019;23(19):8175-85.

120. An JH, et al. LncRNA SNHG16 promoted proliferation and inflammatory response of macrophages through miR-17-5p/NF-kappaB signaling pathway in patients with atherosclerosis. Eur Rev Med Pharmacol Sci. 2019;23(19):8665-77.

121. Li C, et al. LncRNA AWPPH promotes osteosarcoma progression via activation of Wnt/ $\beta$-catenin pathway through modulating miR-93-3p/ FZD7 axis. Biochem Biophys Res Commun. 2019;514(3):1017-22.

122. Wu WJ, et al. Integrated analysis of long non-coding RNA competing interactions revealed potential biomarkers in cervical cancer: based on a public database. Mol Med Rep. 2018;17(6):7845-58.

123. Amarin Z, Badria L, Obeidat B. Attitudes and beliefs about cervical smear testing in ever-married Jordanian women. East Mediterr Health J. 2008;13:389-97.

124. Song B, et al. Incidence and mortality of cervical cancer in China, 2013. Chin J Cancer Res. 2017;29(6):471.

125. Cui $\mathrm{H}$, et al. Direct downregulation of B-cell translocation gene 3 by microRNA-93 is required for desensitizing esophageal cancer to radiotherapy. Digest Dis Sci. 2017:62(8):1995-2003.

126. Xiong $\mathrm{Y}$, et al. iASPP induces EMT and cisplatin resistance in human cervical cancer through miR-20a-FBXL5/BTG3 signaling. J Exp Clin Cancer Res. 2017;36(1):48.

127. Li J, et al. Suppression of miR-93-5p inhibits high-risk HPV-positive cervical cancer progression via targeting of BTG3. Hum Cell. 2019;32(2):160-71. 
128. Takashima Y, et al. MicroRNA signature constituted of miR-30d, miR-93, and miR-181 b is a promising prognostic marker in primary central nervous system lymphoma. PLoS ONE. 2019;14(1):e0210400.

129. Wang $Y$, Jiang $T$. Understanding high grade glioma: molecular mechanism, therapy and comprehensive management. Cancer Lett. 2013;331(2):139-46.

130. Sathornsumetee S, Rich JN. New treatment strategies for malignant gliomas. Expert Rev Anticancer Therapy. 2006;6(7):1087-104.

131. Louis DN, et al. The 2007 WHO classification of tumours of the central nervous system. Acta Neuropathol. 2007;114(2):97-109.

132. Zhang L, Liang X, Li Y. Long non-coding RNA MEG3 inhibits cell growth of gliomas by targeting miR-93 and inactivating PI3K/AKT pathway. Oncol Rep. 2017;38(4):2408-16.

133. Jiang $L$, et al. miR-93 promotes cell proliferation in gliomas through activation of PI3K/Akt signaling pathway. Oncotarget. 2015;6(10):8286.

134. Yang $Y$, et al. miR-93-5p may be an important oncogene in prostate cancer by bioinformatics analysis. J Cell Biochem. 2019;120(6):10463-83.

135. Davies MA, et al. Regulation of Akt/PKB activity, cellular growth, and apoptosis in prostate carcinoma cells by MMAC/PTEN. Cancer Res. 1999;59(11):2551-6.

136. Hsiung SC, et al. Roles of extracellular signal-regulated kinase and Akt signaling in coordinating nuclear transcription factor-KB-dependent cell survival after serotonin $1 \mathrm{~A}$ receptor activation. J Neurochem. 2005:95(6):1653-66.

137. Torrealba N, et al. Expression of ERK1 and ERK2 in prostate cancer. MAP Kinase. 2012;2012:169170.

138. Yang K, et al. MiR-93 functions as a tumor promoter in prostate cancer by targeting disabled homolog 2 (DAB2) and an antitumor polysaccharide from green tea (Camellia sinensis) on their expression. Int J Biol Macromol. 2019;125:557-65.

139. Ha T, et al. Identification of epithelial-specific ETS-1 (ESE-1) as a tumor suppressor and molecular target of green tea compound, EGCG. Mol Carcinog. 2019;58(6):922-32.

140. Karihtala P, et al. Expression levels of microRNAs miR-93 and miR-200a in pancreatic adenocarcinoma with special reference to differentiation and relapse-free survival. Oncology. 2019;96(3):164-70.

141. Liang $\mathrm{H}$, et al. Down-regulation of RE-1 silencing transcription factor (REST) in advanced prostate cancer by hypoxia-induced miR-106b 25 . Exp Cell Res. 2014;320(2):188-99.

142. Tchaicha JH, et al. Glioblastoma angiogenesis and tumor cell invasiveness are differentially regulated by $\beta 8$ integrin. Cancer Res. 2011;71(20):6371-81.

143. Summerer l, et al. Changes in circulating microRNAs after radiochemotherapy in head and neck cancer patients. Radiat Oncol. 2013;8(1):296.

144. Liu J-J, Zhang X, Wu X-H. miR-93 promotes the growth and invasion of prostate cancer by upregulating its target genes TGFBR2, ITGB8, and LATS2. Mol Ther Oncolyt. 2018;11:14-9.

145. Jiménez $\mathrm{G}$, et al. Relief of gene repression by torso RTK signaling: role of capicua in Drosophila terminal and dorsoventral patterning. Genes Dev. 2000;14(2):224-31.

146. Lee $\mathrm{Y}$, et al. ATXN1 protein family and CIC regulate extracellular matrix remodeling and lung alveolarization. Dev Cell. 2011;21(4):746-57.

147. Kim E, et al. Deficiency of Capicua disrupts bile acid homeostasis. Sci Rep. 2015;5:8272.

148. Sjöblom T, et al. The consensus coding sequences of human breast and colorectal cancers. Science. 2006;314(5797):268-74.

149. Kan Z, et al. Diverse somatic mutation patterns and pathway alterations in human cancers. Nature. 2010;466(7308):869.

150. Alentorn A, Sanson M, Idbaih A. Oligodendrogliomas: new insights from the genetics and perspectives. Curr Opin Oncol. 2012;24(6):687-93.

151. Choi N, et al. miR-93/miR-106b/miR-375-CIC-CRABP1: a novel regulatory axis in prostate cancer progression. Oncotarget. 2015;6(27):23533.

152. Torre LA, et al. Global cancer statistics, 2012. CA Cancer J Clin. 2015;65(2):87-108.

153. Siegel RL, Miller KD, Jemal A. Cancer statistics, 2015. CA Cancer J Clin. 2015;65(1):5-29.

154. Deng $L$, et al. Long noncoding RNA CCAT1 promotes hepatocellular carcinoma progression by functioning as let-7 sponge. J Exp Clin Cancer Res. 2015;34(1):18.

155. Gibb EA, et al. Human cancer long non-coding RNA transcriptomes. PLOS ONE. 2011:6(10):e25915.
156. Du Z, et al. Integrative genomic analyses reveal clinically relevant long noncoding RNAs in human cancer. Nat Struct Mol Biol. 2013;20(7):908.

157. Huarte M. The emerging role of IncRNAs in cancer. Nat Med. 2015;21(11):1253.

158. Esteller M. Non-coding RNAs in human disease. Nat Rev Genet. 2011;12(12):861.

159. Xu F, et al. Overexpressing IncRNA SNHG16 inhibited HCC proliferation and chemoresistance by functionally sponging hsa-miR-93. OncoTargets Therapy. 2018;11:8855.

160. Fu Y, et al. Long non-coding RNAs, ASAP1-IT1, FAM215A, and LINC00472, in epithelial ovarian cancer. Gynecol Oncol. 2016;143(3):642-9.

161. Shen Y, et al. LINC00472 expression is regulated by promoter methylation and associated with disease-free survival in patients with grade 2 breast cancer. Breast Cancer Res Treat. 2015;154(3):473-82.

162. Shen Y, et al. Prognostic and predictive values of long non-coding RNA LINC00472 in breast cancer. Oncotarget. 2015;6(11):8579.

163. Chen L, et al. Regulatory network analysis of LINC00472, a long noncoding RNA downregulated by DNA hypermethylation in colorectal cancer. Clin Genet. 2018:93(6):1189-98.

164. Chen C, et al. Long non-coding RNA LINC00472 suppresses hepatocellular carcinoma cell proliferation, migration and invasion through miR-93-5p/PDCD4 pathway. Clin Res Hepatol Gastroenterol. 2019;43(4):436-45.

165. Ng K-Y, et al. TP53INP1 downregulation activates a p73-dependent DUSP10/ERK signaling pathway to promote metastasis of hepatocellular carcinoma. Cancer Res. 2017;77(17):4602-12.

166. Ding J, et al. Long noncoding RNA CRNDE promotes colorectal cancer cell proliferation via epigenetically silencing DUSP5/CDKN1A expression. Cell Death Dis. 2017;8(8):e2997.

167. Xue $\mathrm{X}$, et al. Exosomal miR-93 promotes proliferation and invasion in hepatocellular carcinoma by directly inhibiting TIMP2/TP53INP1/ CDKN1A. Bioch Biophys Res Commun. 2018;502(4):515-21.

168. Charos $A E$, et al. A highly integrated and complex PPARGC1A transcription factor binding network in HepG2 cells. Genome Res. 2012;22(9):1668-79.

169. Kamimura $\mathrm{N}$, et al. Molecular hydrogen stimulates the gene expression of transcriptional coactivator PGC-1 a to enhance fatty acid metabolism. NPJ Aging Mech Dis. 2016;2:16008.

170. Spiegelman PP. Peroxisome proliferator-activated receptor-gamma coactivator 1 alpha (PGC-1 alpha): transcriptional coactivator and metabolic regulator. Endocr Rev. 2003;24:78-90.

171. Liu R, et al. Peroxisome proliferator-activated receptor gamma coactivator-1 alpha acts as a tumor suppressor in hepatocellular carcinoma. Tumor Biol. 2017;39(4):1010428317695031.

172. Wang $X$, et al. MiR-93-5p Promotes cell proliferation through downregulating PPARGC1A in hepatocellular carcinoma cells by bioinformatics analysis and experimental verification. Genes. 2018;9(1):51.

173. Zhang $H$, et al. Involvement of programmed cell death 4 in transforming growth factor- $\beta 1$-induced apoptosis in human hepatocellular carcinoma. Oncogene. 2006;25(45):6101.

174. Li JZH, et al. The clinical association of programmed cell death protein 4 (PDCD4) with solid tumors and its prognostic significance: a metaanalysis. Chin J Cancer. 2016;35(1):95.

175. Wang $\mathrm{Q}$, et al. Down-regulation of programmed cell death 4 leads to epithelial to mesenchymal transition and promotes metastasis in mice. Eur J Cancer. 2013;49(7):1761-70.

176. Ji C, et al. miR-93 enhances hepatocellular carcinoma invasion and metastasis by EMT via targeting PDCD4. Biotechnol Lett. 2017:39(11):1621-9.

177. Huang $\mathrm{H}$, et al. The miR-93 promotes proliferation by directly targeting PDCD4 in hepatocellular carcinoma. Neoplasma. 2017;64(5):770-7.

178. Samarghandian S, et al. Inhibitory and cytotoxic activities of chrysin on human breast adenocarcinoma cells by induction of apoptosis. Harmacogn Mag. 2016;12(Suppl 4):S436.

179. Samarghandian S, et al. Antiproliferative activity and induction of apoptotic by ethanolic extract of Alpinia galanga rhizhome in human breast carcinoma cell line. BMC Complement Altern Med. 2014;14:192.

180. Xiong W, Dong J, Kong S. Dentatin exerts anticancer effects on human colon cancer cell lines via cell cycle arrest, autophagy. 
inhibition of cell migration and JAK/STAT signalling pathway. J Buon. 2019;24(4):1488-93.

181. Verhoeven Y, et al. The potential and controversy of targeting STAT family members in cancer. Semin Cancer Biol. 2020;60:41-56.

182. Dong $Z$, et al. STAT gene family mRNA expression and prognostic value in hepatocellular carcinoma. Onco Targets Ther. 2019;12:7175-91.

183. Toh TB, et al. Targeting Jak/Stat pathway as a therapeutic strategy against SP/CD44+ tumorigenic cells in Akt/beta-catenin-driven hepatocellular carcinoma. J Hepatol. 2020;72(1):104-18.

184. Li JP, et al. Long noncoding RNA H19 competitively binds miR93-5p to regulate STAT3 expression in breast cancer. J Cell Biochem. 2019;120(3):3137-48

185. Ni Q, et al. Different signatures of miR-16, miR-30b and miR93 in exosomes from breast cancer and DCIS patients. Sci Rep. 2018;8(1):12974

186. Haynes $B$, et al. RAD6B is a major mediator of triple negative breast cancer cisplatin resistance: regulation of translesion synthesis/Fanconi anemia crosstalk and BRCA1 independence. Biochim Biophys Acta Mol Basis Dis. 2020;1866(1):165561.

187. Attia YM, et al. Inhibition of aldehyde dehydrogenase-1 and p-glycoprotein-mediated multidrug resistance by curcumin and vitamin D3 increases sensitivity to paclitaxel in breast cancer. Chem Biol Interact. 2020;315:108865. https://doi.org/10.1016/j.cbi.2019.108865.

188. Wang $Q$, et al. Mechanism of the enhancing effects of miR-93 on resistance of breast cancer MCF-7 cells to adriamycin. Oncol Lett. 2020;315:108865. https://doi.org/10.1016/j.cbi.2019.108865.

189. Lamouille $\mathrm{S}$, et al. Regulation of epithelial-mesenchymal and mesenchymal-epithelial transitions by microRNAs. Curr Opin Cell Biol. 2013;25(2):200-7.

190. Zaravinos A. The regulatory role of microRNAs in EMT and cancer. J Oncol. 2015:2015:865816. https://doi.org/10.1155/2015/865816.

191. Li C, et al. MicroRNA-21 promotes TGF- $\beta 1$-induced epithelial-mesenchymal transition in gastric cancer through up-regulating PTEN expression. Oncotarget. 2016;7(41):66989.

192. Li H, et al. MicroRNA-181a regulates epithelial-mesenchymal transition by targeting PTEN in drug-resistant lung adenocarcinoma cells. Int J Oncol. 2015;47(4):1379-92.

193. Brozovic A. The relationship between platinum drug resistance and epithelial-mesenchymal transition. Archiv Toxicol. 2017;91(2):605-19.

194. Huang J, Li H, Ren G. Epithelial-mesenchymal transition and drug resistance in breast cancer. Int J Oncol. 2015;47(3):840-8.

195. Du B, Shim JS. Targeting epithelial-mesenchymal transition (EMT) to overcome drug resistance in cancer. Molecules. 2016;21(7):965.

196. Bugide S, et al. HPIP promotes epithelial-mesenchymal transition and cisplatin resistance in ovarian cancer cells through PI3K AKT pathway activation. Cell Oncol. 2017:40(2):133-44

197. Miao Y, et al. MicroRNA-130b targets PTEN to mediate drug resistance and proliferation of breast cancer cells via the PI3K/Akt signaling pathway. Sci Rep. 2017;7:41942.

198. Xia H, Ooi LLP, Hui KM. MicroRNA-216a/217-induced epithelial-mesenchymal transition targets PTEN and SMAD7 to promote drug resistance and recurrence of liver cancer. Hepatology. 2013;58(2):629-41.

199. Chu S, et al. miR-93 and PTEN: key regulators of doxorubicin-resistance and EMT in breast cancer. Oncol Rep. 2017;38(4):2401-7.

200. Li N, et al. MiR-106b and miR-93 regulate cell progression by suppression of PTEN via PI3K/Akt pathway in breast cancer. Cell Death Dis. 2017;8(5):e2796.

201. Xiang Y, et al. MiR-93-5p inhibits the EMT of breast cancer cells via targeting MKL-1 and STAT3. Exp Cell Res. 2017;357(1):135-44.

202. Moniz S, Jordan P. Emerging roles for WNK kinases in cancer. Cell Mol Life Sci. 2010;67(8):1265-76.

203. Xie J, et al. Endothelial-specific expression of WNK1 kinase is essential for angiogenesis and heart development in mice. Am J Pathol. 2009;175(3):1315-27.

204. Lai J-G, et al. Zebrafish WNK lysine deficient protein kinase 1 (wnk1) affects angiogenesis associated with VEGF signaling. PLOS ONE. 2014;9(8):e106129.

205. Lee B-H, et al. Biological cross-talk between WNK1 and the transforming growth factor $\beta$-Smad signaling pathway. J Biol Chem. 2007:282(25):17985-96.
206. Wilson FH, et al. Human hypertension caused by mutations in WNK kinases. Science. 2001;293(5532):1107-12.

207. Xu B-E, et al. WNK1 activates SGK1 to regulate the epithelial sodium channel. Proc Natl Acad Sci. 2005;102(29):10315-20.

208. Shyamasundar S, Lim JP, Bay BH. miR-93 inhibits the invasive potential of triple-negative breast cancer cells in vitro via protein kinase WNK1. Int J Oncol. 2016:49(6):2629-36.

209. Wang L, et al. miR-93-3p inhibition suppresses clear cell renal cell carcinoma proliferation, metastasis and invasion. Oncotarget. 2017:8(47):82824

210. Jemal A, et al. Global cancer statistics. CA Cancer J Clin. 2011:61(2):69-90.

211. Isomoto $\mathrm{H}$, et al. Endoscopic submucosal dissection for early gastric cancer: a large-scale feasibility study. Gut. 2009;58(3):331-6.

212. Espinel J, et al. Treatment modalities for early gastric cancer. World J Gastrointest Endosc. 2015;7(12):1062.

213. Ferlay J, et al. Estimates of worldwide burden of cancer in 2008: GLOBOCAN 2008. Int J Cancer. 2010;127(12):2893-917.

214. Larki P, Ahadi A. Up-regulation of miR-21, miR-25, miR-93, and miR-106b in gastric cancer. Iran Biomed J. 2018:22(6):367.

215. Harvey KF, Zhang X, Thomas DM. The Hippo pathway and human cancer. Nat Rev Cancer. 2013;13(4):246.

216. Yu F-X, Zhao B, Guan K-L. Hippo pathway in organ size control, tissue homeostasis, and cancer. Cell. 2015;163(4):811-28.

217. Plouffe SW, Hong AW, Guan K-L. Disease implications of the Hippo/YAP pathway. Trends Mol Med. 2015;21(4):212-22.

218. Ehmer U, Sage J. Control of proliferation and cancer growth by the Hippo signaling pathway. Mol Cancer Res. 2016;14(2):127-40.

219. Jiao $S$, et al. A peptide mimicking VGLL4 function acts as a YAP antagonist therapy against gastric cancer. Cancer Cell. 2014;25(2):166-80.

220. Kang W, et al. Emerging role of Hippo pathway in gastric and other gastrointestinal cancers. World J Gastroenterol. 2016;22(3):1279.

221. Zang ZJ, et al. Exome sequencing of gastric adenocarcinoma identifies recurrent somatic mutations in cell adhesion and chromatin remodeling genes. Nat Genet. 2012;44(5):570.

222. Li L, et al. MiR-93-5p promotes gastric cancer-cell progression via inactivation of the Hippo signaling pathway. Gene. 2018;641:240-7.

223. Meng $\mathrm{H}$, et al. MiRNA-93-5p promotes the biological progression of gastric cancer cells via Hippo signaling pathway. Eur Rev Med Pharmacol Sci. 2019;23(11):4763-9.

224. Tang $\mathrm{S}$, et al. Association analyses of the JAK/STAT signaling pathway with the progression and prognosis of colon cancer. Oncol Lett. 2019;17(1):159-64.

225. Patel MR, et al. JAK/STAT inhibition with ruxolitinib enhances oncolytic virotherapy in non-small cell lung cancer models. Cancer Gene Ther. 2019;26:411-8

226. Ma D-H, et al. miR-93-5p/IFNAR1 axis promotes gastric cancer metastasis through activating the STAT3 signaling pathway. Cancer Lett. 2017:408:23-32.

227. Araya RE, Goldszmid RS. IFNAR1 degradation: a new mechanism for tumor immune evasion? Cancer Cell. 2017;31(2):161-3.

228. Yu H, et al. Revisiting STAT3 signalling in cancer: new and unexpected biological functions. Nat Rev Cancer. 2014:14(11):736.

229. Yang C-H, et al. Direct association of STAT3 with the IFNAR-1 chain of the human type I interferon receptor. J Biol Chem. 1996;271(14):8057-61.

230. Schneider WM, Chevillotte MD, Rice CM. Interferon-stimulated genes: a complex web of host defenses. Ann Rev Immunol. 2014;32:513-45.

231. Zhang $R$, et al. Long non-coding RNA PTENP1 functions as a ceRNA to modulate PTEN level by decoying miR-106b and miR-93 in gastric cancer. Oncotarget. 2017;8(16):26079.

232. Liang $\mathrm{H}$, et al. miR-93 functions as an oncomiR for the downregulation of PDCD4 in gastric carcinoma. Sci Rep. 2016;6:23772.

233. Church DN, et al. Prognostic significance of POLE proofreading mutations in endometrial cancer. J Natl Cancer Inst. 2015;107(1):402. https:// doi.org/10.1093/jnci/dju402.

234. Gunderson CC, et al. The impact of obesity on surgical staging, complications, and survival with uterine cancer: a Gynecologic Oncology Group LAP2 ancillary data study. Gynecol Oncol. 2014;133(1):23-7.

235. Fang $\mathrm{S}$, et al. Expression of serum Hsa-miR-93 in uterine cancer and its clinical significance. Oncol Lett. 2018;15(6):9896-900. 
236. Weis E, et al. Epithelial lacrimal gland tumors: pathologic classification and current understanding. Arch Ophthalmol. 2009;127(8):1016-28.

237. Bernardini FP, Devoto MH, Croxatto JO. Epithelial tumors of the lacrimal gland: an update. Curr Opin Ophthalmol. 2008;19(5):409-13.

238. von Holstein $\mathrm{SL}$, et al. Adenoid cystic carcinoma of the lacrimal gland: MYB gene activation, genomic imbalances, and clinical characteristics. Ophthalmology. 2013;120(10):2130-8.

239. Esmaeli B, et al. Outcomes in patients with adenoid cystic carcinoma of the lacrimal gland. Ophthalm Plast Reconstruct Surg. 2004;20(1):22-6.

240. David TT, et al. Clinical analysis of the effect of intraarterial cytoreductive chemotherapy in the treatment of lacrimal gland adenoid cystic carcinoma. Am J Ophthalmol. 2006;141(1):44-53.

241. Meldrum ML, David TT, Benedetto P. Neoadjuvant intracarotid chemotherapy for treatment of advanced adenocystic carcinoma of the lacrimal gland. Archiv Ophthalmol. 1998;116(3):315-21.

242. Hao J, et al. miR-93-5p enhance lacrimal gland adenoid cystic carcinoma cell tumorigenesis by targeting BRMS1L. Cancer Cell Int. 2018;18(1):72.

243. Edmonds MD, et al. Breast cancer metastasis suppressor 1 coordinately regulates metastasis-associated microRNA expression. Int I Cancer. 2009;125(8):1778-85.

244. Phadke PA, et al. BRMS1 suppresses breast cancer experimental metastasis to multiple organs by inhibiting several steps of the metastatic process. Am J Pathol. 2008;172(3):809-17.

245. Shevde LA, et al. Suppression of human melanoma metastasis by the metastasis suppressor gene, BRMS1. Exp Cell Res. 2002;273(2):229-39.

246. Smith PW, et al. Breast cancer metastasis suppressor 1 (BRMS1) suppresses metastasis and correlates with improved patient survival in non-small cell lung cancer. Cancer Lett. 2009;276(2):196-203.

247. Siegel RL, Miller KD, Jemal A. Cancer statistics, 2016. CA Cancer J Clin. 2016;66(1):7-30.

248. Ferlay J, et al. Cancer incidence and mortality patterns in Europe: estimates for 40 countries in 2012. Eur J Cancer. 2013:49(6):1374-403.

249. Chen X, et al. MiR-93 targeting EphA4 promotes neurite outgrowth from spinal cord neurons. J Mol Neurosci. 2016;58(4):517-24.

250. Ryan DP, Hong TS, Bardeesy N. Pancreatic adenocarcinoma. N Engl J Med. 2014;371(11):1039-49.

251. Kayed $\mathrm{H}$, et al. Regulation and functional role of the Runt-related transcription factor-2 in pancreatic cancer. Br J Cancer. 2007;97(8):1106.

252. Whittle MC, et al. RUNX3 controls a metastatic switch in pancreatic ductal adenocarcinoma. Cell. 2015;161(6):1345-60.

253. Whittle MC, Hingorani SR. RUNX3 defines disease behavior in pancreatic ductal adenocarcinoma. Mol Cell Oncol. 2016;3(2):e1076588.

254. Banerji S, et al. Sequence analysis of mutations and translocations across breast cancer subtypes. Nature. 2012;486(7403):405.

255. Ellis MJ, et al. Whole-genome analysis informs breast cancer response to aromatase inhibition. Nature. 2012;486(7403):353.

256. Planagumà J, et al. A differential gene expression profile reveals overexpression of RUNX1/AML1 in invasive endometrioid carcinoma. Cancer Res. 2004;64(24):8846-53.

257. Doll A, et al. An orthotopic endometrial cancer mouse model demonstrates a role for RUNX1 in distant metastasis. Int J Cancer. 2009:125(2):257-63.

258. Cheng Y, et al. RUNX1 promote invasiveness in pancreatic ductal adenocarcinoma through regulating miR-93. Oncotarget. 2017:8(59):99567.

259. Capitanio U, Montorsi F. Renal cancer. Lancet. 2016;387(10021):894-906.

260. Cros J, et al. Nestin expression on tumour vessels and tumour-infiltrating macrophages define a poor prognosis subgroup of pt1 clear cell renal cell carcinoma. Virchows Arch. 2016:469(3):331-7.

261. Gu L, et al. MicroRNAs as prognostic molecular signatures in renal cell carcinoma: a systematic review and meta-analysis. Oncotarget. 2015:6(32):32545

262. Kamińska K. et al. Interleukin-6 as an emerging regulator of renal cell cancer. In: Urologic oncology: seminars and original investigations. 2015. Elsevier

263. Motzer RJ, et al. Pazopanib versus sunitinib in metastatic renal-cell carcinoma. N Engl J Med. 2013;369(8):722-31.

264. Granovetter M. Benefits of pazopanib over sunitinib for renal cell carcinoma. Lancet Oncol. 2016;17(3):e93.
265. Robinson SP, et al. Monitoring the vascular response and resistance to sunitinib in renal cell carcinoma in vivo with susceptibility contrast MRI. Cancer Res. 2017;77(15):4127-34.

266. Mejias $\mathrm{M}$, et al. Antiangiogenic and antifibrogenic activity of pigment epithelium-derived factor (PEDF) in bile duct-ligated portal hypertensive rats. Gut. 2015;64(4):657-66.

267. Becerra SP, Notario V. The effects of PEDF on cancer biology: mechanisms of action and therapeutic potential. Nat RevCancer. 2013:13(4):258.

268. Wolf $\mathrm{G}$, et al. High glucose-induced hypertrophy of mesangial cells requires p27Kip1, an inhibitor of cyclin-dependent kinases. Am J Pathol. 2001;158(3):1091-100.

269. Galliher AJ, Neil JR, Schiemann WP. Role of transforming growth factorbeta in cancer progression. Future Oncol. 2006;2(6):743-63. https://doi. org/10.2217/14796694.2.6.743.

270. Sengupta S, Kundu S, Bhattacharyya A. Attenuation of Smad2 activity shows resistance to TGF- $\beta$ signalling in mammary adenocarcinoma (MCF-7) cells. Cell Biol Int. 2013;37(5):449-57.

271. Connolly EC, Freimuth J, Akhurst RJ. Complexities of TGF- $\beta$ targeted cancer therapy. Int J Biol Sci. 2012;8(7):964

272. Drabsch Y, Ten Dijke P. TGF- $\beta$ signalling and its role in cancer progression and metastasis. Cancer Metastasis Rev. 2012;31(3-4):553-68.

273. Ramp U, et al. Acquisition of TGF-beta 1 resistance: an important progression factor in human renal cell carcinoma. Lab Investig. 1997;76(5):739-49.

274. Hahn SA, et al. DPC4, a candidate tumor suppressor gene at human chromosome 18q21. 1. Science. 1996;271(5247):350-3.

275. Shi J, et al. TGF-beta induced RBL2 expression in renal cancer cells by down-regulating miR-93. Clin Transl Oncol. 2014;16(11):986-92.

276. Raman JD, Jafri SM. Surgical management of bladder urothelial carcinoma with squamous differentiation. In: Urologic oncology: seminars and original investigations. 2015. Elsevier.

277. Kiselyov A, Bunimovich-Mendrazitsky S, Startsev V. Treatment of nonmuscle invasive bladder cancer with Bacillus Calmette-Guerin (BCG): biological markers and simulation studies. BBA Clin. 2015;4:27-34.

278. Massari F, et al. Emerging concepts on drug resistance in bladder cancer: implications for future strategies. Crit Rev Oncol Hematol. 2015;96(1):81-90.

279. Vallo S, et al. Drug-resistant urothelial cancer cell lines display diverse sensitivity profiles to potential second-line therapeutics. Transl Oncol. 2015;8(3):210-6.

280. Soukup V, et al. Follow-up after surgical treatment of bladder cancer: a critical analysis of the literature. Eur Urol. 2012;62(2):290-302.

281. Garg M. Prognostic and therapeutic applications of the molecular events in clinical management of urothelial carcinoma of bladder. J Exp Ther Oncol. 2014;10(4):301-16.

282. Balar AV, Milowsky MI. Neoadjuvant therapy in muscle-invasive bladder cancer: a model for rational accelerated drug development. Urol Clin. 2015;42(2):217-24.

283. Braicu C, et al. Clinical and pathological implications of miRNA in bladder cancer. Int J Nanomed. 2015:10:791.

284. Noon AP, Catto JW. Noncoding RNA in bladder cancer: a specific focus upon high-risk nonmuscle invasive disease. Curr Opin Urol. 2014;24(5):506-11.

285. Liu J, et al. Repression of the miR-93-enhanced sensitivity of bladder carcinoma to chemotherapy involves the regulation of LASS2. OncoTargets Therapy. 2016;9:1813.

286. Fan S, et al. LASS2 enhances chemosensitivity of breast cancer by counteracting acidic tumor microenvironment through inhibiting activity of V-ATPase proton pump. Oncogene. 2013;32(13):1682.

287. Yildiz Y, et al. High expression of mesothelin in advanced serous ovarian cancer is associated with poor prognosis. J Buon. 2019;24(4):1549-54.

288. Kubelac $\mathrm{P}$, et al. The clinical features associated with mutated BRCA1 and 2 genes in ovarian cancer patients. J Buon. 2019;24(4):1538-43.

289. Cao Y, et al. MiR-125a-5p inhibits EMT of ovarian cancer cells by regulating TAZ/EGFR signaling pathway. Eur Rev Med Pharmacol Sci. 2019;23(19):8249-56.

290. Liu XL, et al. PCAT1 promotes the proliferative and migratory potentials of ovarian cancer via targeting NEK2. Eur Rev Med Pharmacol Sci. 2019:23(19):8239-48. 
291. Kumar S, et al. Coiled-coil and C2 domain-containing protein $1 \mathrm{~A}$ (CC2D1A) promotes chemotherapy resistance in ovarian cancer. Front Oncol. 2019;9:986.

292. Sirois AR, et al. Engineered Fn3 protein has targeted therapeutic effect on mesothelin-expressing cancer cells and increases tumor cell sensitivity to chemotherapy. Biotechnol Bioeng. 2020;117(2):330-41.

293. Lee JH, et al. Brusatol, a Nrf2 inhibitor targets STAT3 signaling cascade in head and neck squamous cell carcinoma. Biomolecules. 2019;9(10):550.

294. Halim CE, et al. Anti-cancer effects of oxymatrine are mediated through multiple molecular mechanism (s) in tumor models. Pharmacol Res. 2019;147:104327. https://doi.org/10.1016/j.phrs.2019.104327.

295. Kim C, et al. Formononetin regulates multiple oncogenic signaling cascades and enhances sensitivity to bortezomib in a multiple myeloma mouse model. Biomolecules. 2019;9(7):262.

296. Mirhadi E, Rezaee M, Malaekeh-Nikouei B. Nano strategies for berberine delivery, a natural alkaloid of Berberis. Biomed Pharmacother. 2018;104:465-73.

297. Hesari A, et al. Berberine: a potential adjunct for the treatment of gastrointestinal cancers? J Cell Biochem. 2018;119(12):9655-63.

298. Chen Q, et al. Berberine sensitizes human ovarian cancer cells to cisplatin through miR-93/PTEN/Akt signaling pathway. Cell Physiol Biochem 2015:36(3):956-65.

299. Meng X, et al. Diagnostic and prognostic potential of serum miR-7, miR16, miR-25, miR-93, miR-182, miR-376a and miR-429 in ovarian cancer patients. Br J Cancer. 2015;113(9):1358.

300. The L. Toward better control of colorectal cancer. Lancet. 2014;383(9927):1437.

301. Böckelman C, et al. Risk of recurrence in patients with colon cancer stage II and III: a systematic review and meta-analysis of recent literature. Acta Oncol. 2015;54(1):5-16.

302. Ma Y, et al. Long non-coding RNA CCAL regulates colorectal cancer progression by activating Wnt/ $\beta$-catenin signalling pathway via suppression of activator protein 2a. Gut. 2016;65(9):1494-504.

303. Wei H, Yang Z, Lin B. Overexpression of long non coding RNA CA3-AS1 suppresses proliferation, invasion and promotes apoptosis via miRNA93/PTEN axis in colorectal cancer. Gene. 2019;687:9-15.

304. Hanahan D, Weinberg RA. Hallmarks of cancer: the next generation. Cell. 2011;144(5):646-74.

305. Ribatti D, et al. Angiogenesis and antiangiogenesis in triple-negative breast cancer. Transl Oncol. 2016;9(5):453-7.

306. Sharma SG, Nanda S, Longo S. Anti-angiogenic therapy in renal cell carcinoma. Recent Patents Anti-Cancer Drug Discov. 2010;5(1):77-83.

307. Welker M-W, Trojan J. Anti-angiogenesis in hepatocellular carcinoma treatment: current evidence and future perspectives. World J Gastroenterol. 2011;17(26):3075.

308. Vasudev NS, Reynolds AR. Anti-angiogenic therapy for cancer: current progress, unresolved questions and future directions. Angiogenesis. 2014;17(3):471-94.
309. Liang $L$, et al. MiR-93-5p enhances growth and angiogenesis capacity of HUVECs by down-regulating EPLIN. Oncotarget. 2017;8(63):107033.

310. Sanders AJ, et al. The impact of EPLINa (Epithelial protein lost in neoplasm) on endothelial cells, angiogenesis and tumorigenesis. Angiogenesis. 2010;13(4):317-26.

311. Li YJ, et al. Long non-coding RNA ZNF667-AS1 reduces tumor invasion and metastasis in cervical cancer by counteracting microRNA-93-3pdependent PEG3 downregulation. Mol Oncol. 2019;13:2375-92.

312. Gong J, et al. L-Tetrahydropalmatine enhances the sensitivity of human ovarian cancer cells to cisplatin via microRNA-93/PTEN/Akt cascade. J Buon. 2019;24(2):701-8.

313. Jiang $\mathrm{H}$. et al. MicroRNA-93 promotes bladder cancer proliferation and invasion by targeting PEDF. In: Urologic oncology: seminars and original investigations. 2019. Elsevier.

314. Zhang X, Li F, Zhu L. Clinical significance and functions of microRNA-93/ CDKN1A axis in human cervical cancer. Life Sci. 2018;209:242-8.

315. Guan $\mathrm{H}$, et al. MicroRNA-93 promotes proliferation and metastasis of gastric cancer via targeting TIMP2. PLoS ONE. 2017;12(12):e0189490.

316. Yu X, et al. Long intergenic non-protein-coding RNA 1567 (LINC01567) acts as a "sponge" against microRNA-93 in regulating the proliferation and tumorigenesis of human colon cancer stem cells. BMC Cancer. 2017;17(1):716-716.

317. Chen S, et al. MicroRNA-93 promotes epithelial-mesenchymal transition of endometrial carcinoma cells. PLoS ONE. 2016;11(11):e0165776.

318. Chen $\mathrm{X}$, et al. RhoC is a major target of microRNA-93-5P in epithelial ovarian carcinoma tumorigenesis and progression. Mol Cancer. 2015;14:31.

319. Tang Q, et al. MicroRNA-93 suppress colorectal cancer development via Wnt/beta-catenin pathway downregulating. Tumour Biol. 2015;36(3):1701-10.

320. Xiao X, et al. MicroRNA-93 regulates cyclin G2 expression and plays an oncogenic role in laryngeal squamous cell carcinoma. Int J Oncol. 2015;46(1):161-74.

321. Hu J, et al. Identification of microRNA-93 as a functional dysregulated miRNA in triple-negative breast cancer. Tumour Biol. 2015;36(1):251-8.

322. Singh B, et al. MicroRNA-93 regulates NRF2 expression and is associated with breast carcinogenesis. Carcinogenesis. 2013;34(5):1165-72.

323. Xiao ZG, et al. Clinical significance of microRNA-93 downregulation in human colon cancer. Eur J Gastroenterol Hepatol. 2013;25(3):296-301.

324. Yang IP, et al. MicroRNA-93 inhibits tumor growth and early relapse of human colorectal cancer by affecting genes involved in the cell cycle. Carcinogenesis. 2012;33(8):1522-30.

325. Fu X, et al. Involvement of microRNA-93, a new regulator of PTEN/Akt signaling pathway, in regulation of chemotherapeutic drug cisplatin chemosensitivity in ovarian cancer cells. FEBS Lett. 2012;586(9):1279-86.

\section{Publisher's Note}

Springer Nature remains neutral with regard to jurisdictional claims in published maps and institutional affiliations.
Ready to submit your research? Choose BMC and benefit from:

- fast, convenient online submission

- thorough peer review by experienced researchers in your field

- rapid publication on acceptance

- support for research data, including large and complex data types

- gold Open Access which fosters wider collaboration and increased citations

- maximum visibility for your research: over $100 \mathrm{M}$ website views per year

At BMC, research is always in progress.

Learn more biomedcentral.com/submissions 